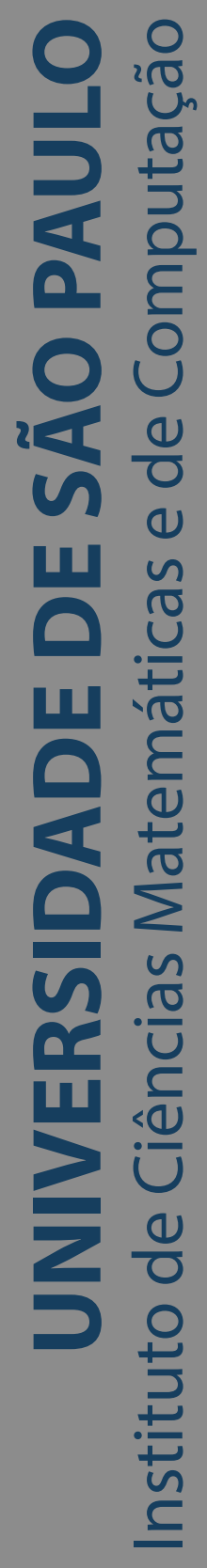

\title{
Mineração de Regras de Exceção em Séries Temporais
} Multivariadas

\section{Thábata Amaral}

Dissertação de Mestrado do Programa de Pós-Graduação em Ciências de Computação e Matemática Computacional (PPG-CCMC) 

Assinatura:

\title{
Thábata Amaral
}

\section{Mineração de Regras de Exceção em Séries Temporais Multivariadas}

\begin{abstract}
Dissertação apresentada ao Instituto de Ciências Matemáticas e de Computação - ICMC-USP, como parte dos requisitos para obtenção do título de Mestra em Ciências - Ciências de Computação e Matemática Computacional. VERSÃO REVISADA

Área de Concentração: Ciências de Computação e Matemática Computacional

Orientadora: Profa. Dra. Elaine Parros Machado de Sousa
\end{abstract}


Ficha catalográfica elaborada pela Biblioteca Prof. Achille Bassi e Seção Técnica de Informática, ICMC/USP, com os dados inseridos pelo(a) autor(a)

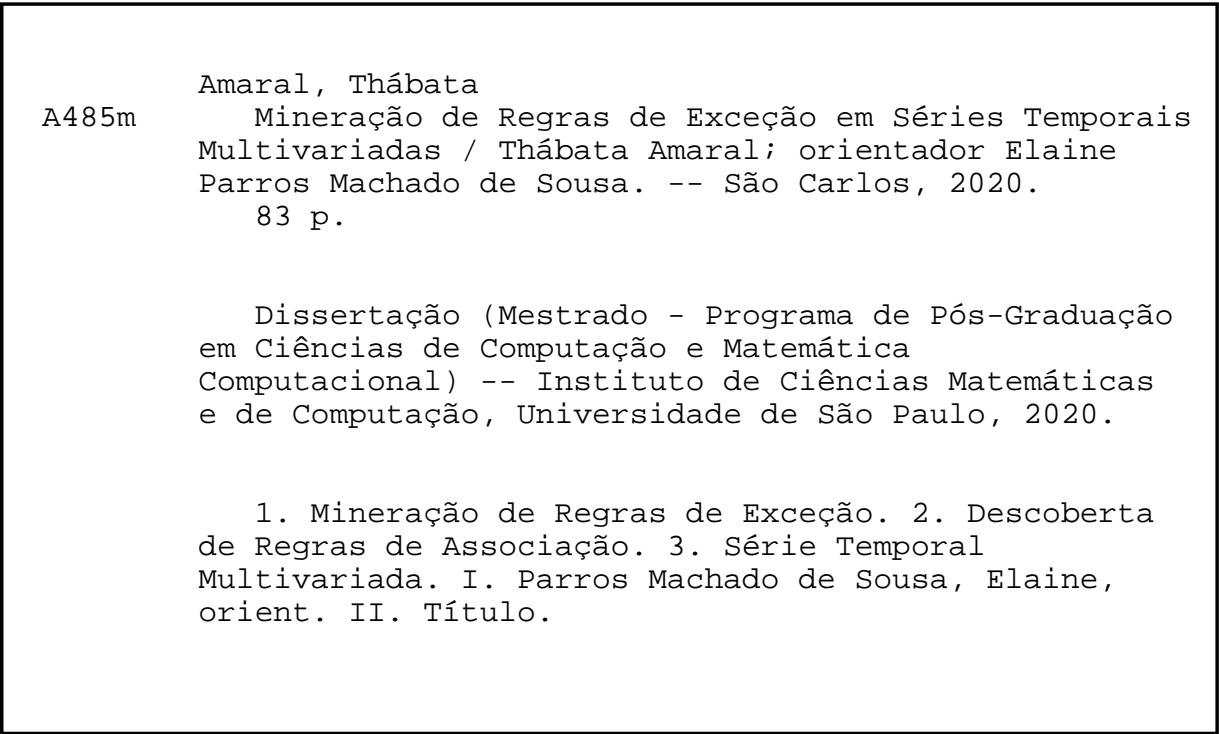

Bibliotecários responsáveis pela estrutura de catalogação da publicação de acordo com a AACR2: Gláucia Maria Saia Cristianini - CRB - 8/4938

Juliana de Souza Moraes - CRB - 8/6176 


\section{Thábata Amaral}

\section{Exception Rules Mining in Multivariate Time Series}

Master dissertation submitted to the Institute of Mathematics and Computer Sciences - ICMC-USP, in partial fulfillment of the requirements for the degree of the Master Program in Computer Science and Computational Mathematics. FINAL VERSION

Concentration Area: Computer Science and Computational Mathematics

Advisor: Profa. Dra. Elaine Parros Machado de Sousa

USP - São Carlos

May 2020 

À Deus pelo dom da vida.

Aos meus pais Antonio e Silvia, pelo incondicional amor e incentivo nos momentos mais difíceis. Obrigada por viverem este sonho comigo.

À minha família, em especial às minhas irmãs Ingrid, Ághata e Ângela que mesmo com a distância dos últimos anos confiaram em mim e fizeram-se presentes nesta jornada.

À minha orientadora Profa. Dra. Elaine, pelo tempo, amizade e esforço investidos. Obrigada por aflorar meu amor pela ciência e por me tornar uma pessoa melhor.

Ao meu namorado Marco Antônio, pelo companheirismo e fundamental apoio sempre que precisei. Aos amigos do GBDI, em especial Lucas Kunze, Lucas Santiago, Patricia e Jadson por tornarem a caminhada mais agradável.

À Universidade de São Paulo por toda estrutura e recursos que me forneceu. Aos professores e funcionários do ICMC-USP que direta ou indiretamente contribuíram para a execução deste trabalho. A CNPq e CAPES pelo apoio financeiro à realização deste trabalho.

A todos vocês, o meu muito obrigada. 

"A única coisa que temos e que mais ninguém tem somos nós mesmos. Nossa voz, nossa história, nossa visão. Por isso, escreva, desenhe, construa, brinque e viva apenas como você pode." 



\section{RESUMO}

AMARAL, T. Mineração de Regras de Exceção em Séries Temporais Multivariadas. 2020. 83 p. Dissertação (Mestrado em Ciências - Ciências de Computação e Matemática Computacional) - Instituto de Ciências Matemáticas e de Computação, Universidade de São Paulo, São Carlos - SP, 2020.

A tarefa de Descoberta de Regras de Associação tem o objetivo de descobrir relacionamentos úteis e compreensivos em dados frequentes e infrequentes. Enquanto padrões frequentes descrevem um comportamento comum, padrões infrequentes representam comportamentos que raramente ocorrem. O interesse deste trabalho reside em encontrar regras de exceção, isto é, padrões que embora ocorram com pouca frequência, possuem efeitos potencialmente críticos como consequência. As abordagens existentes para Mineração de Regras de Exceção lidam com “ bases de dados de itemsets", em que as transações são organizadas sem informação temporal. No entanto, a temporalidade pode ser inerente a alguns contextos reais e deve ser considerada para melhorar a qualidade semântica dos resultados. Além disso, a maioria dessas abordagens possui alto custo computacional (de ordem exponencial), tornando-se inviáveis para minerar grandes volumes de dados. Com o objetivo de superar essas limitações, este trabalho propõe TRiER

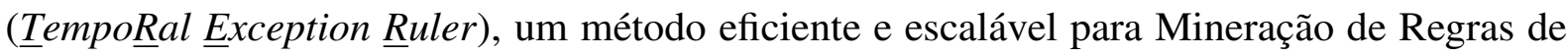
Exceção Temporais. Especificamente, o método proposto não apenas descobre comportamentos excepcionais e seus respectivos agentes causadores, mas também identifica quanto tempo as consequências demoram para aparecer. Foi realizada uma análise experimental em dados reais para verificar a aplicabilidade prática do TRiER. Os resultados obtidos mostram que o método possui menor custo computacional e é mais escalável do que os métodos correlatos, além de encontrar regras com maior relevância semântica.

Palavras-chave: Mineração de Regras de Exceção, Descoberta de Regras de Associação, Série Temporal Multivariada. 



\section{ABSTRACT}

AMARAL, T. Exception Rules Mining in Multivariate Time Series. 2020. 83 p. Dissertação (Mestrado em Ciências - Ciências de Computação e Matemática Computacional) - Instituto de Ciências Matemáticas e de Computação, Universidade de São Paulo, São Carlos - SP, 2020.

Association rules are a common task to discover useful and comprehensive relationships among frequent and infrequent items. Frequent patterns describe a common behavior for certain conditions. Infrequent patterns, on the other hand, represent behavior that rarely occurs. Our interest lies in finding exception rules, i.e., patterns that although occurring infrequently have potentially critical effects as a consequence. Existing approaches for exception rule mining usually handle "itemsets databases", where transactions are organized with no temporal information. However, temporality may be inherent to some real contexts and should be considered to improve the semantic quality of results. Moreover, most of these approaches have high computational cost (of exponential order), becoming unfeasible for mining large datasets. Aiming to overcome these

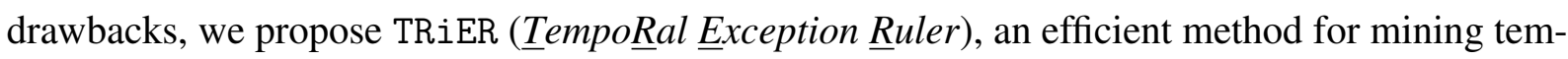
poral exception rules. Especially, our method does not only discover exceptional behaviors and their causative agents, but also identifies how long consequences take to appear. We performed an extensive experimental analysis in real data to verify the practical applicability of TRiER. Our results shows TRiER has lower computational cost and is more scalable than existing approaches while finding rules with greater semantic relevance.

Keywords: Exception Rule Mining, Association Rules, Multivariate Time Series. 



\section{LISTA DE ILUSTRAÇÕES}

Figura 1 - Exemplo de séries univariada e multivariada . . . . . . . . . . . . . 29

Figura 2 - O método binning . . . . . . . . . . . . . . . 30

Figura 3 - Suavização por média móvel . . . . . . . . . . . . . . . 31

Figura 4 - Piecewise Aggregate Approximation . . . . . . . . . . . . . . 32

Figura 5 - Symbolic Aggregate approXimation . . . . . . . . . . . . 33

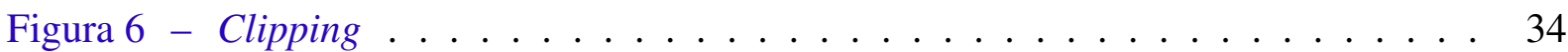

Figura 7 - Discretizações equal-width e equal-frequency. . . . . . . . . . . . 34

Figura 8 - O processo de KDD . . . . . . . . . . . . . . . 38

Figura 9 - Exemplo de padrão sequencial no mercado varejista . . . . . . . . . . . 42

Figura 10 - Junção de sequências . . . . . . . . . . . . . . . . . . . . . . 44

Figura 11 - Exemplos de prefixos . . . . . . . . . . . . . . . . 46

Figura 12 - Exemplo de regra de exceção em medicina . . . . . . . . . . . . . . . . . . . . . . . . .

Figura 13 - TRiER: visão geral . . . . . . . . . . . . . . . . . . . 52

Figura 14 - Exemplo de conjunto de séries temporais para o TRiER . . . . . . . . . 52

Figura 15 - Junção de sequências com uma observação e $n$ variáveis . . . . . . . . . . . 54

Figura 16 - Junção de sequências com $p$ observações e $n$ variáveis . . . . . . . . . . . . 54

Figura 17 - Classificação de regras fortes e infrequentes . . . . . . . . . . . . . . . . 57

Figura 18 - Mapeamento do conjunto agrometeorológico: estações meteorológicas e áreas de cana-de-açúcar do estado de São Paulo . . . . . . . . . . . . . . . 65

Figura 19 - Dados agrometeorológicos: tempo médio gasto em mineração de sequências, em minutos . . . . . . . . . . . . . . . . . . . . . . 68

Figura 20 - Dados agrometeorológicos: sequências geradas pelo TRiER e Prefix-Span para $5 \%$ de suporte . . . . . . . . . . . . . . . . . . 69

Figura 21 - Dados de El-Niño: tempo médio gasto em mineração de sequências, em minutos . . . . . . . . . . . . . . . . 70

Figura 22 - Dados de El-Niño: sequências geradas pelo TRiER e Prefix-Span para 5\% de suporte . . . . . . . . . . . . . . . . . 70

Figura 23 - Dados agrometeorológicos: tempo médio gasto pelo ERSA e TRiER na mineração de regras de exceção . . . . . . . . . . . . . . . . . . . .

Figura 24 - Dados de El-Niño: tempo médio gasto pelo ERSA e TRiER na mineração de regras de exceção . . . . . . . . . . . . . . . . . . . . . . 72

Figura 25 - Transformação de séries temporais em itemset sem perder a informação temporal .......................... 73 



\section{LISTA DE ALGORITMOS}

Algoritmo 1 - Mineração de Sequências do TRiER . . . . . . . . . . . . . 55

Algoritmo 2 - Mineração de Regras de Exceção do TRiER . . . . . . . . . . . . . 58 

Tabela 1 - Transações de Cestas de Compras . . . . . . . . . . . . . . . . . . . . 39

Tabela 2 - Exemplo de Banco de Dados em Formato Horizontal . . . . . . . . . . 42

Tabela 3 - Exemplo de Banco de Dados em Formato Vertical . . . . . . . . . . . . . 43

Tabela 4 - Exemplo de Banco de Transações . . . . . . . . . . . . . . . . . . . . . 49

Tabela 5 - Mapeamento do Banco de Transações para um Banco Binário . . . . . . . . 49

Tabela 6 - Comparativo do TRiER e Trabalhos Relacionados . . . . . . . . . . . . 61

Tabela 7 - Descrição do Conjunto de Dados Agrometeorológico . . . . . . . . . . 65

Tabela 8 - Descrição do Conjunto de Dados El Niño . . . . . . . . . . . . . . . . 66

Tabela 9 - Discretização Equal-Width para os Dados Agrometeorológicos . . . . . . . 66

Tabela 10 - Discretização Equal-Width para os Dados de El-Niño . . . . . . . . . . . . 66

Tabela 11 - Dados Agrometeorológicos: Tempo Médio Gasto em Mineração de Sequências, em Minutos . . . . . . . . . . . . . . . . . . . 67

Tabela 12 - Comparação do Ganho Médio entre os Métodos TRiER e Prefix-Span . . . . 69

Tabela 13 - Dados de El-Niño: Tempo Médio Gasto em Mineração de Sequências, em Minutos . . . . . . . . . . . . . . . . . . . . 69 



\title{
LISTA DE ABREVIATURAS E SIGLAS
}

\author{
GSP Generalized Sequential Patterns \\ KDD Knowledge Discovery in Databases \\ Prefix-Span Prefix-Projected Sequential Pattern Growth \\ SPADE Sequential Pattern Discovery using Equivalent classes \\ ERSA Exception Rule Search Algorithm \\ FERSA Fuzzy Exceptional Rule Search Algorithm \\ PAA Piecewise Aggregate Approximation \\ SAX Symbolic Aggregate approXimation
}



$S$ - Série Temporal

$p$ - Número de observações da série

$n$ - Número de variáveis da série

$D B$ - Banco de Dados

$T$ - Conjunto de transações

I - Itemset

$X$ - Antecedente da regra

$Y$ - Consequente da regra

sup - Suporte

conf - Confiança

minsup — Suporte mínimo

minconf - Confiança mínima

$f c-$ Fator de certeza

minc $f$ - Fator de certeza mínimo

Seq - Sequência

$E$ - Agente causador da exceção

$\neg Y$ - Comportamento excepcional

$w-$ Window

sup $_{\text {TRIER }}$ - Suporte do TRiER

minsup $_{\text {TRiER }}$ - Suporte mínimo do TRiER

$t_{\text {lag }}$ - Time lag

$\operatorname{conf}_{\text {TRIER }}$ - Confiança do TRiER

minconf $f_{T R E R}$ - Confiança mínima do TRiER

$f c_{\text {TRIER }}$ - Fator de certeza do TRiER

$\min f c_{T R E R}$ - Fator de certeza mínimo do TRiER 

INTRODUÇÃO . . . . . . . . . . . . . . . . . 25

1.1 Contextualização e Motivação . . . . . . . . . . . . . . 26

1.2 Contribuições do Trabalho . . . . . . . . . . . . . . 27

$1.3 \quad$ Organização do Trabalho . . . . . . . . . . . . . . 28

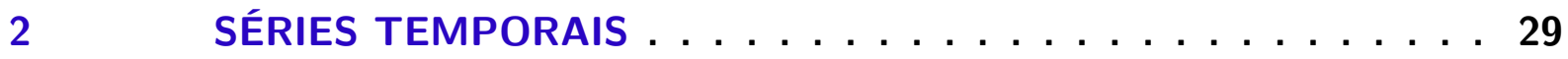

2.1 Pré-Processamento dos Dados . . . . . . . . . . . . . 30

2.2 Representação de Séries Temporais . . . . . . . . . . . . . . 31

2.2.1 Piecewise Aggregate Approximation (PAA) . . . . . . . . . . . 32

2.2.2 Symbolic Aggregate approXimation $(S A X) \ldots \ldots 33$

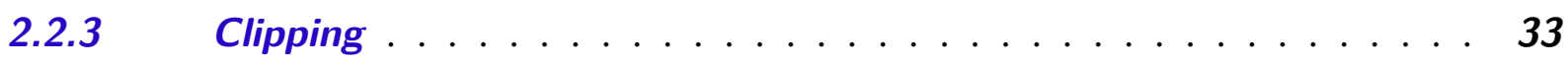

2.2.4 Equal-width e Equal-frequency . . . . . . . . . . . . . . . 34

2.2.5 A Escolha do Método de Representação . . . . . . . . . . . . . . 35

$2.3 \quad$ Considerações Finais . . . . . . . . . . . . . . . . 35

3 MINERAÇÃO DE DADOS E TRABALHOS RELACIONADOS . . . 37

$3.1 \quad$ Descoberta de Regras de Associação . . . . . . . . . . . . 38

3.1.1 O algoritmo Apriori . . . . . . . . . . . . . . 41

3.2 Mineração de Sequências . . . . . . . . . . . . . . . . 41

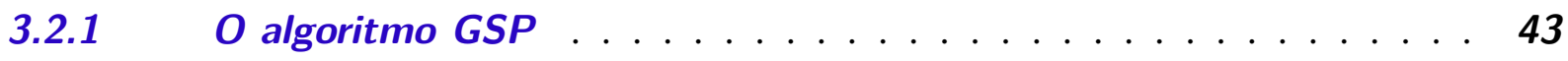

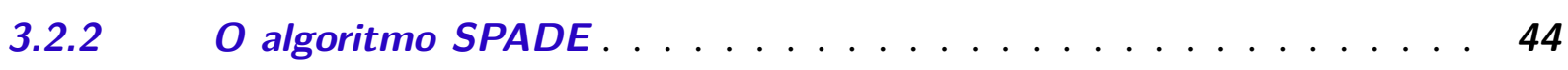

3.2.3 O algoritmo PrefixSpan ................... 45

$3.3 \quad$ Mineração de Regras de Exceção . . . . . . . . . . . . . 47

3.3.1 O algoritmo ERSA . . . . . . . . . . . . . . . 49

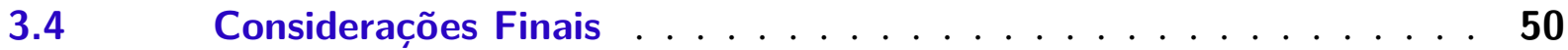

4 O MÉTODO TRIER . . . . . . . . . . . . . . 51

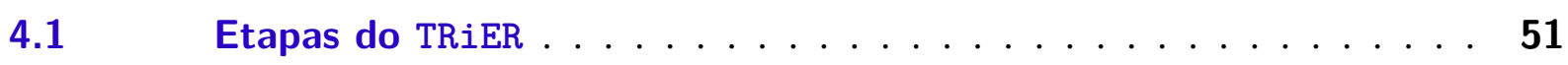

4.2 Mineração de Sequências . . . . . . . . . . . . . 53

$4.3 \quad$ Descoberta de Regras . . . . . . . . . . . . . . 55

$4.4 \quad$ Mineração de Regras de Exceção . . . . . . . . . . . . . . . 57

$4.5 \quad$ Implementação e Complexidade . . . . . . . . . . . . 59

$4.6 \quad$ Considerações Finais . . . . . . . . . . . . . . 60 
EXPERIMENTOS . . . . . . . . . . . . . . . 63

$5.1 \quad$ Conjuntos de Dados Reais . . . . . . . . . . . . . . 63

5.1.1 Dados Agrometeorológicos . . . . . . . . . . . . . . . 64

5.1.2 Dados de El Niño . . . . . . . . . . . . . . . . . . . 65

5.1.3 Representação dos Dados . . . . . . . . . . . . . . . . 66

$5.2 \quad$ Análise Experimental . . . . . . . . . . . . . 66

5.2.1 Mineração de Sequências . . . . . . . . . . . . . . 67

5.2.2 Mineração de Regras de Exceção . . . . . . . . . . . . . . . . . 71

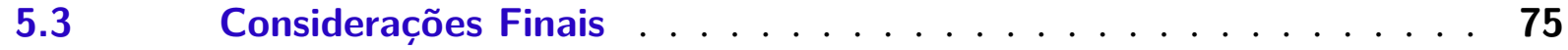

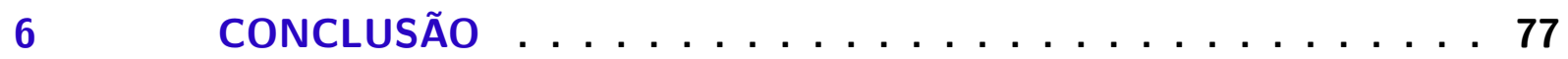

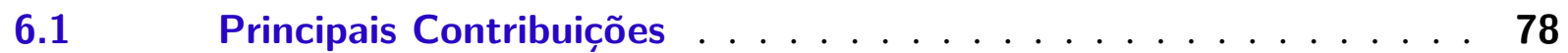

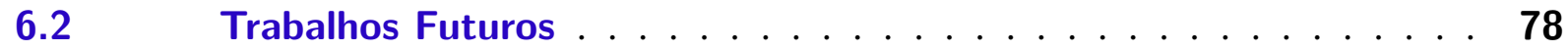

REFERÊNCIAS . . . . . . . . . . . . . . . . . 81 


\section{1}

\section{INTRODUÇÃO}

O volume de séries temporais gerado em diversos domínios de aplicação tem aumentado rapidamente, assim como o número de bases de dados responsáveis por armazená-los. Esses repositórios são relevantes fontes de conhecimento para diversas áreas de pesquisa, empresas privadas e até mesmo o setor público. Dado que a extração de conhecimento a partir de grandes volumes de dados é manualmente inviável, torna-se necessário o desenvolvimento de métodos computacionais eficazes e eficientes para manipular tais dados.

Uma das abordagens mais utilizadas para esta finalidade é o processo de descoberta de conhecimento em bases de dados (do inglês Knowledge Discovery in Databases (KDD)), cujo propósito é extrair conhecimento implícito, previamente desconhecido e potencialmente útil a partir dos dados (FAYYAD; UTHURUSAMY, 1996). Este processo é composto, principalmente, pelas etapas de Seleção, Pré-Processamento, Transformação, Mineração de Dados e Avaliação.

Resumidamente, entende-se o domínio de aplicação e os objetivos finais para selecionar o conjunto de dados de interesse (Seleção). Como este conjunto pode apresentar dados irrelevantes, redundantes e faltantes, torna-se necessário que seja tratado em um processo de integração, limpeza e padronização (Pré-Processamento). Feito isso, define-se a estrutura e representação adequada dos dados, a fim de facilitar a aplicação de tarefas de Mineração de Dados (Transformação). Na próxima etapa, escolhe-se e executa-se a tarefa de mineração para extrair os padrões de interesse, de acordo com os objetivos pré-definidos (Mineração de Dados). Por fim, os padrões obtidos são avaliados para verificar sua relevância e utilidade (Avaliação).

Dentre as etapas de $K D D$, a de Mineração de Dados é a que mais recebe ênfase na literatura, sendo muitas vezes tratada como sinônimo de $K D D$. Vale ressaltar que $K D D$ é algo mais robusto, pois refere-se à totalidade do processo, enquanto Mineração de Dados consiste na aplicação de tarefas específicas, como Classificação, Agrupamento, Descoberta de Regras de Associação, Mineração de Sequências e Mineração de Regras de Exceção. Este trabalho está particularmente interessado nas tarefas de Descoberta de Regras de Associação (AGRAWAL; 
IMIELINSKI; SWAMI, 1993), Mineração de Sequências (AGRAWAL; SRIKANT, 1995) e Mineração de Regras de Exceção (SUZUKI, 1996; HUSSAIN et al., 2000; DELGADO; RUIZ; SANCHEZ, 2010).

A tarefa de Descoberta de Regras de Associação possui muitas aplicações práticas por expressar o conhecimento de modo intuitivo para os especialistas de domínio. O propósito é descobrir relacionamentos frequentes e confiáveis, denominados regras fortes. Um exemplo trivial de regra forte é: "com o auxílio de antibióticos, o paciente tende a se recuperar", a qual é denotada por: antibióticos $\rightarrow$ recuperação, onde antibióticos é o antecedente e recuperação é o consequente da regra.

Em geral, a tarefa de Descoberta de Regras de Associação é realizada em bases de dados transacionais (bases de itemsets), em que os dados são organizados sem informação temporal. No entanto, a temporalidade é inerente a alguns domínios de aplicação e precisa ser considerada para melhorar a qualidade semântica dos resultados. Desse modo, ampliando o conceito de regras de associação, surgem tarefas direcionadas à descoberta de padrões sequenciais, como a Mineração de Sequências. Um exemplo de padrão sequencial é a evolução dos sintomas de gripe de um paciente no decorrer do tempo: "dor de garganta é seguida de tosse e coriza". Este padrão é denotado por: dor de garganta, tosse, coriza.

As tarefas mencionadas são úteis quando o especialista pretende encontrar padrões frequentes, mas não se aplicam quando o interesse é descobrir padrões excepcionais, que naturalmente são infrequentes, incomuns e inesperados. Abordagens voltadas à descoberta deste tipo de conhecimento denominam-se Mineração de Regras de Exceção. Este trabalho concentrase em descobrir tais regras, que embora ocorram com pouca frequência, podem ter consequências críticas em determinados contextos.

De modo geral, uma regra de exceção relaciona-se a uma regra de associação, pois para minerar uma regra de exceção é preciso encontrar um atributo, isto é, um agente, que altera o consequente de uma regra forte. Um exemplo de regra de exceção é: "o uso de antibióticos e a presença da bactéria estafilococo pode levar à morte", a qual é denotada por: antibióticos e estafilococo $\rightarrow$ morte, onde estafilococo é o agente causador da exceção.

\subsection{Contextualização e Motivação}

Os métodos existentes para Mineração de Regras de Exceção, discutidos na Seção 3.3, possuem algumas particularidades que nem sempre oferecem suporte às características de bases de dados reais, volumosas e complexas. Especificamente, tais métodos apenas tratam dados univariados e assumem que exceções são causadas por um único agente (agente univariado). Além disso, são restritos à manipulação de dados transacionais e, portanto, não lidam com séries temporais. Outra limitação é a alta complexidade computacional e a implementação de medidas pouco seletivas para estimar a relevância de um padrão, podendo gerar um volume muito grande 
de padrões. Em alguns casos, o volume de padrões minerado é tão grande que requer uma tarefa de mineração de dados de segunda ordem para filtrar padrões significativos e eliminar os inconsistentes e desnecessários.

A existência de tais lacunas motivou o desenvolvimento deste trabalho de mestrado, em que o principal objetivo é o desenvolvimento de um novo método de Mineração de Regras de Exceção, denominado TRiER (TempoRal Exception Ruler), que descobre padrões com maior relevância semântica, isto é, regras de exceção temporais e potencialmente causadas por mais de um agente (agente multivariado).

A Mineração de Regras de Exceção pode ser realizada em qualquer domínio de aplicação em que pretende-se descobrir relacionamentos frequentes e confiáveis, respectivos desvios (exceções) e os agentes que potencialmente causaram o comportamento excepcional. Em agrometeorologia, por exemplo, pode-se investigar como eventos climáticos extremos afetam determinada cultura agrícola. Esse estudo pode apoiar a implantação de medidas de controle prévias em regiões similares à analisada para minimizar os impactos mais severos causados por eventos climáticos extremos. Um exemplo de regra de exceção em agrometeorologia que os métodos da literatura descobrem é:

"Chuvas excessivas são responsáveis pelo florescimento das plantações de cana-de-açúcar".

As regras descobertas pelos métodos de Mineração de Regras de Exceção da literatura são incompletas semanticamente, considerando que mais de um agente pode ter causado o comportamento excepcional (florescimento das plantações de cana). Além disso, os efeitos de condições climáticas não costumam ser instantâneos, tornando relevante entender qual o real impacto das consequências no decorrer do tempo. Um exemplo de regra de exceção temporal em agrometeorologia que pode ser descoberta pelo método desenvolvido neste trabalho é:

\footnotetext{
"Chuvas excessivas seguidas de baixas temperaturas são responsáveis pelo

florescimento das plantações de cana-de-açúcar no próximo mês".
}

Este exemplo mostra que o método proposto pode descobrir regras de exceção com maior relevância semântica, identificando os agentes multivariados (chuvas excessivas e baixas temperaturas) que causaram o comportamento excepcional e quanto tempo as consequências demoraram para aparecer (um mês).

\subsection{Contribuições do Trabalho}

Neste trabalho foi desenvolvido um novo método para Mineração de Regras de Exceção Temporais que considera algumas particularidades inerentes a contextos reais, como: 
1. Exceções podem ser causadas por mais de um agente (agentes multivariados).

2. As consequências de uma regra podem ocorrer em um lag temporal. Um lag indica um delay (atraso), em unidades de tempo, entre o início do antecedente e o término do consequente da regra.

3. $\mathrm{O}(\mathrm{s})$ agente(s) causador(es) da exceção não necessariamente ocorre $(\mathrm{m})$ juntamente com o antecedente da regra (o agente também pode ocorrer em um lag temporal).

4. O conjunto de regras obtido deve ser sucinto e com regras mais relevantes, a fim de facilitar o entendimento e interpretação dos especialistas de domínio.

Especificamente, TRiER manipula séries temporais multivariadas e descobre regras potencialmente causadas por mais de um agente. Além disso, descobre regras e agentes que ocorrem em um time lag. TRiER também propõe e implementa uma nova medida para estimar a relevância do padrão, cujo objetivo é diferenciar padrões de eventos meramente ocasionais.

TRiER foi aplicado em séries reais de clima e índices vegetativos de cana-de-açúcar para analisar as consequências de eventos climáticos extremos nos índices vegetativos desta cultura no decorrer do tempo. Além deste domínio, o método foi aplicado em séries climáticas do fenômeno El Niño, a fim de investigar quais variáveis climáticas interferem na criticidade do fenômeno. Os resultados revelam que TRiER possui menor custo computacional e é mais escalável do que os métodos existentes, além de encontrar regras semanticamente mais significativas.

\subsection{Organização do Trabalho}

Neste capítulo, foi apresentado o contexto em que se insere o trabalho, bem como a motivação e principais contribuições. O restante desta dissertação está organizado como segue. O Capítulo 2 apresenta conceitos básicos sobre séries temporais, além de técnicas de préprocessamento e representação. O Capítulo 3 descreve os principais trabalhos relacionados, incluindo os de Descoberta de Regras de Associação, Mineração de Sequências e Mineração de Regras de Exceção, destacando suas limitações e principais contribuições. O Capítulo 4 detalha características e funcionamento do método temporal de Mineração de Regras de Exceção proposto, denominado TRIER. O Capítulo 5 sumariza os experimentos realizados e principais resultados obtidos. Por fim, o Capítulo 6 apresenta as conclusões obtidas com este trabalho e possibilidades de trabalhos futuros. 
Uma série temporal consiste em uma sequência de observações ordenadas pelo tempo, com intervalos de tempo regulares entre cada par de observações (MITSA, 2010). Bases de séries temporais são utilizadas em diversas áreas de conhecimento, como em medicina, na geração de eletrocardiogramas; em economia, no acompanhamento das taxas de juros e ações na bolsa de valores; em agricultura, por meio do acompanhamento do vigor vegetativo das safras ao longo do ano e em metereologia, para analisar a evolução de variáveis climáticas ao decorrer das décadas.

Uma série temporal $S=\left\{s_{1}, s_{2}, \ldots, s_{n}\right\}$ em que $s_{i}$, para $i \in\{1, \ldots, n\}$, é uma função discreta com valor $s_{i}$ no instante $t_{i}$. Uma série pode ser univariada (unidimensional) ou multivariada (multidimensional). Se apenas uma variável é utilizada para construir a série, ela é univariada, caso contrário é multivariada. Cada observação $s_{i}$ de uma série temporal multivariada representa um conjunto com $n$ variáveis. A Figura 1 ilustra a diferença entre séries univariadas e multivariadas. A série univariada representa a precipitação ao longo do ano e a multivariada indica uma série meteorológica composta por variáveis de temperatura e umidade relativa do ar.

Figura 1 - Exemplo de séries univariada e multivariada

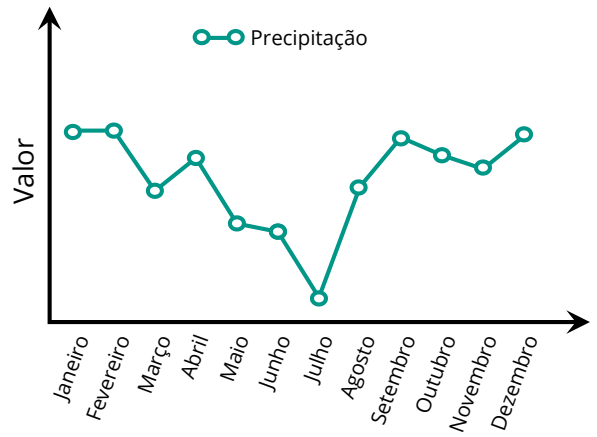

Tempo (mês)

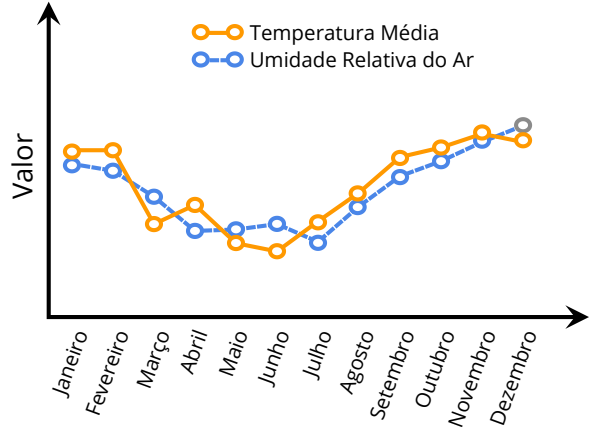

Tempo (mês)

Fonte: Elaborada pelo autor. 
Dado que séries temporais são dados complexos e requerem atividades de pré-processamento e representação para a aplicação de tarefas de Mineração de Dados, este capítulo sumariza métodos clássicos de pré-processamento voltados ao tratamento de ruídos, valores faltantes e normalização de séries temporais (Seção 2.1), além de detalhar particularidades das principais abordagens de representação (Seção 2.2).

\subsection{Pré-Processamento dos Dados}

De modo geral, para que o processo de mineração de séries temporais produza resultados significativos e consistentes, os dados são adequadamente tratados em uma etapa de pré-processamento. O objetivo é eliminar inconsistências que inviabilizam a realização da mineração de dados. Uma das tarefas de pré-processamento em séries temporais é o tratamento de valores faltantes. O problema consiste na ausência de uma ou mais observações da série, que pode ser consequência de falhas em sensores durante a coleta de dados, erro humano ou condições ambientais (MITSA, 2010).

O tratamento de valores faltantes depende da aplicação. Uma alternativa é a substituição desses valores utilizando, por exemplo, algum método de interpolação, como a interpolação polinômial (MITSA, 2010). Na interpolação polinomial, os dados são aproximados por um polinômio de grau conveniente que é utilizado para estimar os dados faltantes. Um grau alto pode gerar uma melhor aproximação dos dados, enquanto um grau menor proporciona um ganho em simplicidade. Uma interpolação com polinômio de grau 1 é chamada de interpolação linear. Há também a possibilidade de não substituir os valores faltantes e utilizar técnicas e funções de distâncias que considerem essa característica durante o processo de análise.

Outra atividade de pré-processamento é o tratamento de ruídos, que são observações com erros de medida e, por isso, apresentam valores inválidos na série temporal. Dois métodos comumente utilizados para tratamento de ruídos são binning e suavização por média móvel (MITSA, 2010). No método binning, as observações da série são divididas em buckets de mesmo tamanho e representadas por algum critério, como a média. A Figura 2 ilustra o método binning utilizando média como critério de representação, formando dois buckets de tamanho cinco.

Figura 2 - O método binning

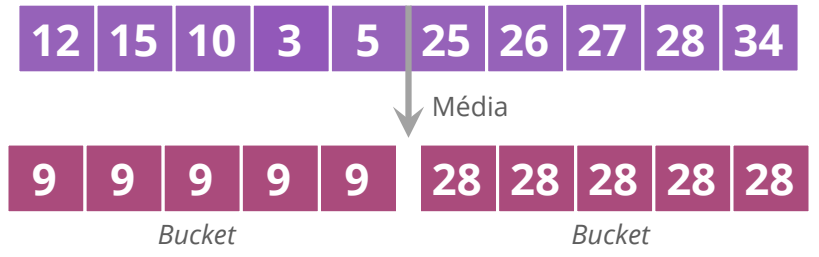

Fonte: Elaborada pelo autor. 
A suavização por média móvel considera valores passados e futuros ao redor de uma observação de interesse e calcula a média entre tais pontos. A Figura 3 apresenta um exemplo de suavização por média móvel considerando apenas um valor passado e um futuro. Na série ilustrada, o valor de média móvel para o instante dois é quatro, pois os valores dos instantes um e três são, respectivamente, um e sete. Vale ressaltar que é possível utilizar mais de um valor ao redor do ponto de interesse.

Figura 3 - Suavização por média móvel

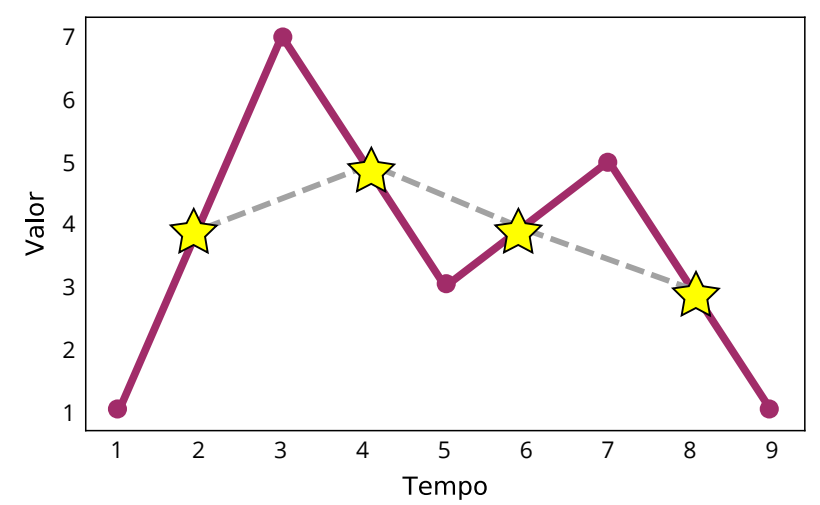

Fonte: Adaptada de Mitsa (2010).

Uma tarefa comum no pré-processamento é a normalização de séries temporais. $\mathrm{O}$ objetivo é representar todas as séries da base de dados em uma mesma escala. Dois tipos de normalização conhecidas são: normalização min-max e z-score.

Para aplicar a normalização min-max é necessário informar o valor que será normalizado $(x)$, juntamente com os valores mínimo $\left(x_{\min }\right)$ e máximo $\left(x_{\max }\right)$ do conjunto de dados, como mostra a Equação 2.1.

$$
x_{\text {norm }}=\frac{x-x_{\min }}{x_{\max }-x_{\min }}
$$

A normalização $z$-score, por outro lado, utiliza a média $\mu$ e o desvio padrão $\sigma$ do conjunto de dados como critério de normalização, conforme apresentado na Equação 2.2:

$$
x_{\text {norm }}=\frac{x-\mu}{x-\sigma}
$$

\subsection{Representação de Séries Temporais}

Séries temporais são dados complexos e, em geral, precisam ser reescritas em uma representação mais concisa e manipulável para os algoritmos de Mineração de Dados. Existem vários métodos de representação de séries temporais, muitos deles com o objetivo de discretizar os dados, já que grande parte dos algoritmos de mineração apenas manipulam séries discretizadas. 
Discretização é o processo de mapeamento de valores contínuos em discretos, sendo utilizada para reduzir o número de valores que um atributo contínuo pode assumir (HAN; KAMBER, 2006). Embora o processo de discretização perca alguns detalhes dos dados originais, os dados generalizados podem ser mais significativos e simples de interpretar, contribuindo para uma representação mais consistente dos resultados dos algoritmos em diferentes tarefas de mineração (CASANOVA et al., 2017). As próximas subseções descrevem os principais métodos de representação de séries temporais que objetivam discretizar os dados.

\subsubsection{Piecewise Aggregate Approximation (PAA)}

O método Piecewise Aggregate Approximation (PAA) (KEOGH et al., 2001) tem por objetivo reduzir a dimensionalidade da série temporal. Para isso, a série original é dividida em $k$ segmentos de mesmo tamanho, sendo representada por um vetor. Desse modo, cada elemento do vetor corresponde à média de cada segmento, como definido na Equação 2.3, em que $\bar{x}_{i}$ representa o i-ésimo elemento da série discretizada, $p$ indica o número de observações da série original e $N$ refere-se à quantidade de observações da nova série.

$$
\bar{x}_{i}=\frac{N}{p} \sum_{j=\frac{p}{N}(i-1)+1}^{\frac{p}{N} i} x_{j}
$$

A Figura 4 ilustra a aplicação do PAA em uma série de quinze observações $(p=15)$. Após a discretização, a série apresenta quatro observações $(N=4)$, que são equivalentes à média aritmética simples dos valores das observações de cada segmento. A série resultante é $S=\{63,58.4,56.6,39\}$.

Figura 4 - Piecewise Aggregate Approximation

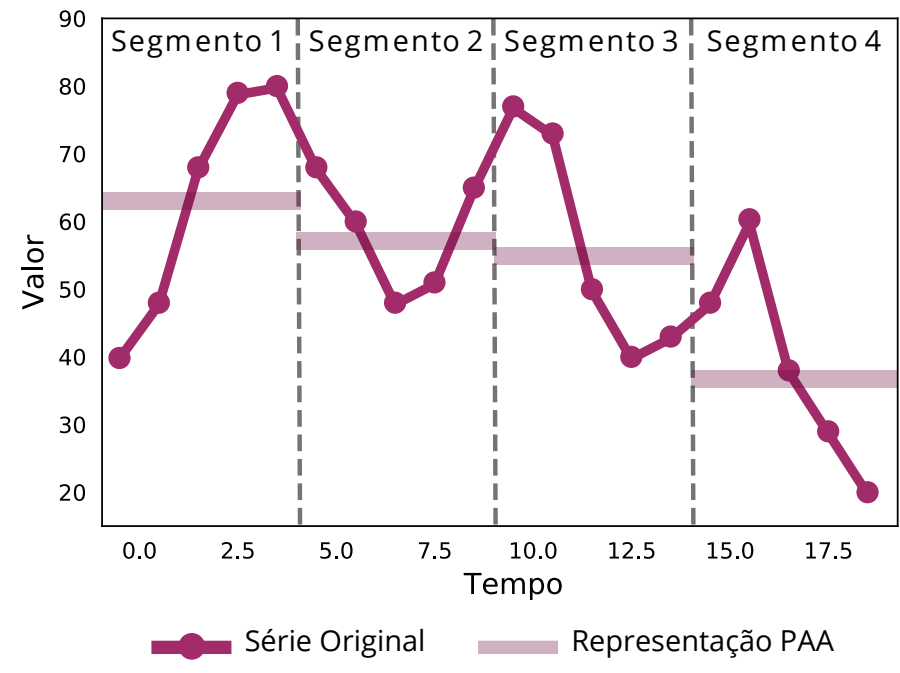

Fonte: Elaborada pelo autor. 


\subsubsection{Symbolic Aggregate approXimation (SAX)}

O método Symbolic Aggregate approXimation (SAX) (LIN et al., 2007) utiliza o PAA como técnica intermediária. Para isso, os segmentos obtidos pelo PAA são representados por meio de símbolos. Apesar de não existir uma regra que determine a quantidade de símbolos a ser utilizada, recomenda-se que esta quantidade seja maior que dois.

SAX considera que os valores da série possuem distribuição normal e fundamenta-se no conceito de equiprobabilidade. Para isso, a série é dividida em $\alpha$ partes que correspondem à cardinalidade da representação, de modo que cada parte compreenda $\frac{1}{\alpha}$ da área abaixo da normal. A Figura 5 ilustra um exemplo de aplicação do SAX para uma série com 20 observações.

Figura 5 - Symbolic Aggregate approXimation
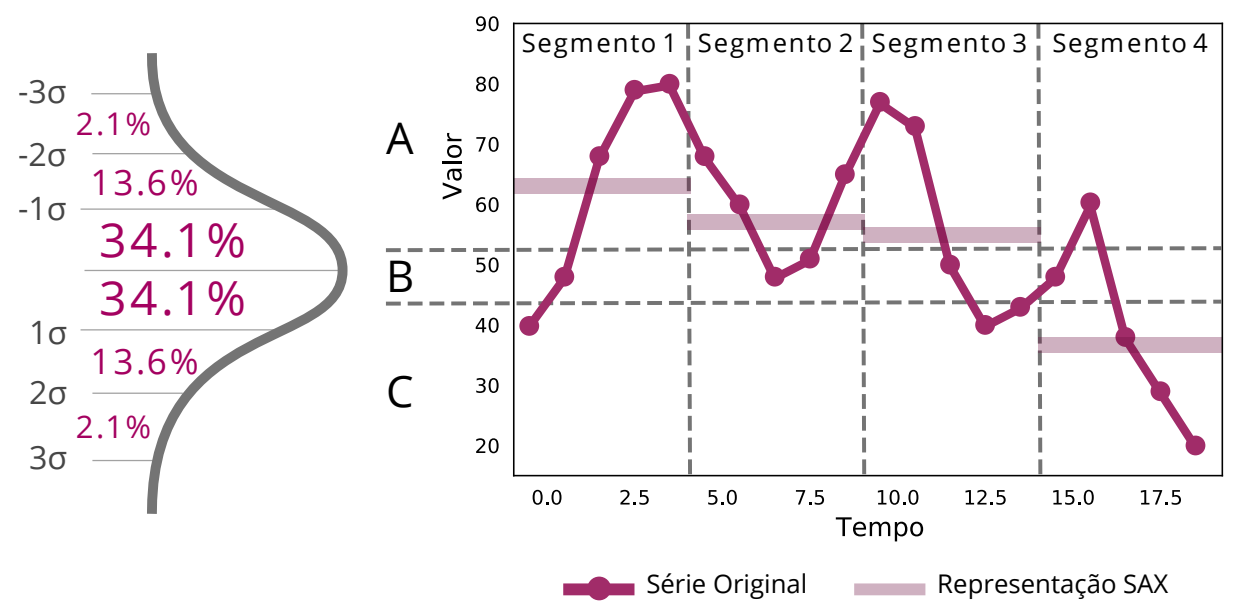

Fonte: Elaborada pelo autor.

Este exemplo considera que os dados estão em distribuição normal, o que permite dividi-los em faixas de mesma probabilidade. Inicialmente, aplica-se o PAA para representar a série temporal em 4 segmentos. Assumindo um alfabeto de tamanho $3(\alpha=3)$, criam-se quatro breakpoints $B_{0}, B_{1}, B_{2}$ e $B_{3}$, sendo $B_{0}=-\infty$ e $B_{3}=+\infty$. Desse modo, cada segmento é associado a um símbolo do alfabeto, conforme a região da normal em que ele está inserido. $\mathrm{O}$ resultado da representação com $\mathrm{SAX}$ para esta série é $S=\{a, a, a, c\}$.

\subsubsection{Clipping}

O método clipping tem por objetivo representar uma série temporal em uma sequência de bits (MITSA, 2010). Para isso, define-se um referencial de comparação, como a média, para analisar os valores da série. Se o valor de uma observação da série for maior do que o valor considerado como critério, esta observação recebe valor 1 , caso contrário recebe 0 . A Figura 6 ilustra o método de clipping para uma série com 13 observações e utiliza a média aritmética simples como comparativo. O resultado da representação por clipping para esta série é $S=\{0,0,1,1,1,0,1,0,1,1,1,0,0\}$. 
Figura 6 - Clipping

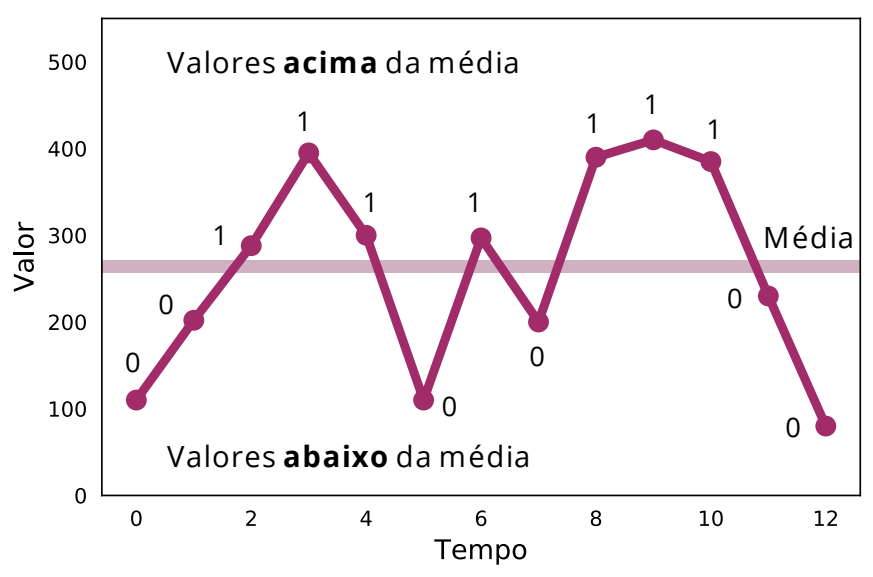

Fonte: Elaborada pelo autor.

\subsubsection{Equal-width e Equal-frequency}

Métodos de discretização mais simples utilizam abordagens equal-width e equal-frequency (ORHAN; HEKIM; OZER, 2012; SULAIMAN; BAKAR, 2016). Abordagens equal-width dividem os valores de modo que as faixas tenham o mesmo tamanho (largura). Abordagens equal-frequency, por outro lado, criam faixas com a mesma quantidade de valores. Assim, para um total de $P$ dados, variando de $a$ até $b$, a discretização equal-width obtém faixas de tamanho $\frac{b-a}{q}$, onde $q$ é o número de faixas desejadas, enquanto a abordagem equal-frequency cria faixas $\operatorname{com} \frac{P}{q}$ dados em cada uma delas. A Figura 7 ilustra um exemplo de discretização equal-width e equal-frequency para 155 dias de precipitação.

Figura 7 - Discretizações equal-width e equal-frequency.
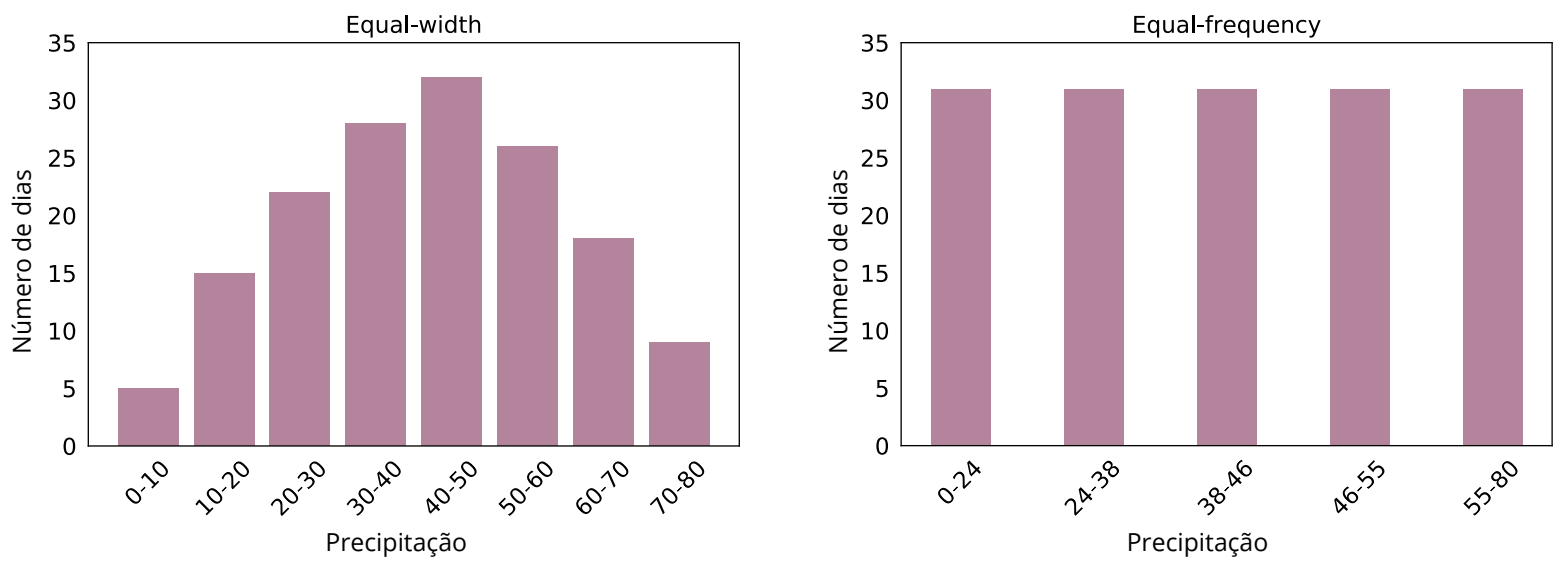

Fonte: Elaborada pelo autor. 
nhos irregulares e agrupam itens pouco frequentes para criar intervalos com a mesma frequência de valores. Como resultado, padrões infrequentes tendem a ser diluídos nessas faixas, o que pode representar perda semântica em tarefas voltadas à mineração de padrões pouco frequentes.

\subsubsection{A Escolha do Método de Representação}

Para as tarefas de mineração de dados utilizadas neste trabalho, o método de representação deve atender às seguintes premissas:

1. Não agrupar padrões infrequentes, distorcendo a frequência com que eles ocorrem. Se isso acontecer, padrões excepcionais e frequentes terão a mesma probabilidade de ocorrer, prejudicando a qualidade a semântica das regras descobertas.

2. Não compactar as observações da série, isto é, evitar que um conjunto de observações seja representado por algum critério, como a média, em uma única observação. Essa generalização pode resultar em uma perca de informação.

3. Agir de maneira independente em cada variável, de modo que ao formar uma série temporal multivariada seja possível discernir o que cada um dos símbolos representa.

A abordagem equal-frequency e o método clipping tendem a agrupar padrões infrequentes e frequentes em uma faixa e não atendem à primeira premissa. Os métodos PAA e SAX reduzem a quantidade de observações das séries, as compactando por algum critério e não satisfazem a segunda premissa. Além disso, o método PAA não atende à terceira condição, uma vez que utiliza a média para representar as informações que foram agrupadas, sendo assim variáveis distintas podem ter o mesmo valor no processo de representação.

Neste contexto, escolheu-se a abordagem equal-width para representação de séries temporais, uma vez que ela satisfaz as três premissas definidas. Entretanto, fica a critério do usuário da aplicação a escolha do método que considerar mais apropriado, contanto que satisfaça as premissas definidas. Embora existam outras abordagens que atendem as premissas descritas, a equal-width destaca-se por ser intuitiva e simples de implementar.

\subsection{Considerações Finais}

A mineração de séries é um processo que pode resultar em conhecimento útil e inovador, se devidamente aplicada. Por isso, antes de iniciá-la é aconselhável estudar as características e propriedades dos dados que serão manipulados a fim de identificar potenciais problemas. À medida que os problemas forem tratados, evita-se a propagação de inconsistências que podem impactar a qualidade final do processo de mineração. Neste capítulo, abordagens apresentadas com esta finalidade foram: representação, tratamento de valores faltantes e tratamento de ruídos. 
Um método comum para tratamento de valores faltantes é a interpolação linear, que utiliza polinômios de primeiro grau para inferir o valor faltante. Embora possa gerar uma aproximação distante do ideal, em alguns domínios o ganho em simplicidade pode compensar o erro da interpolação. Uma alternativa é a interpolação polinomial, que utiliza polinômios de graus maiores para determinar o valor faltante. A escolha do grau deve ser experimental, considerando o valor que melhor se adequa ao comportamento da série temporal.

Métodos voltados ao tratamento de ruídos, como binning e suavização por média móvel, precisam utilizar bons critérios de suavização para representar a série temporal. A média, por exemplo, tende a compactar os valores, prejudicando a qualidade semântica dos resultados.

Realizadas as etapas de pré-processamento, os dados são representados em um formato mais sucinto para a facilitar a aplicação das tarefas de mineração. Um exemplo é o processo de discretização, que apesar de sumarizar detalhes dos dados, consiste em uma representação padronizada e potencialmente simples de interpretar.

O próximo capítulo descreve o processo de descoberta de conhecimento em bases de dados, destacando as tarefas de mineração que são de interesse para este trabalho e o cenário da literatura, além de identificar possíveis lacunas e limitações de trabalhos relacionados. 


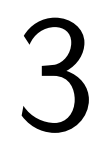

\section{MINERAÇÃO DE DADOS E TRABALHOS RELACIONADOS}

O volume de dados gerado em diversos domínios de aplicação tem crescido consideravelmente, assim como o número de bases de dados responsáveis por armazená-los. Além de volumosas, em muitos casos, as bases armazenam dados complexos, como imagens e séries temporais, o que inviabiliza a análise manual do conteúdo desses repositórios.

Este cenário motiva o desenvolvimento de métodos computacionais capazes de manipular tais dados em tempo e custos factíveis. Uma das abordagens mais utilizadas para esta finalidade é o processo de Descoberta de Conhecimento em Bases de Dados, do inglês Knowledge Discovery in Databases (KDD) (FAYYAD; UTHURUSAMY, 1996).

KDD é definido como o processo iterativo e interativo de identificar padrões novos, válidos, úteis e compreensíveis em bases de dados volumosas e complexas (MAIMON; ROKACH, 2010). Este processo possui natureza interdisciplinar e tem intersecção com múltiplas áreas de pesquisa, como aprendizado de máquina, banco de dados, estatística e visualização de dados. O objetivo comum é a extração de conhecimento em alto nível de abstração a partir da análise de grandes volumes de dados em baixo nível de abstração. A Figura 8 ilustra as etapas que compõem o processo de KDD, sumarizadas a seguir.

- Seleção de Dados: consiste na primeira etapa do processo e tem como objetivo restringir o domínio da aplicação e o conjunto de dados que será utilizado ao longo do processo. Como os dados podem ser provenientes de diferentes fontes, é importante selecioná-los e combiná-los adequadamente para obter as informações pretendidas.

- Pré-Processamento e Limpeza: etapa designada ao tratamento de ruídos e dados inconsistentes e faltantes. O propósito geral é tratá-los em um processo de integração, limpeza e padronização, oferecendo maior eficácia para os algoritmos de mineração de dados. 
- Transformação: define-se a estrutura e representação adequada dos dados, a fim de facilitar a aplicação de tarefas de mineração. Um exemplo de transformação é a discretização de valores contínuos em intervalos de mesmo tamanho.

- Mineração de Dados: escolhe-se e executa-se a tarefa de mineração de dados mais apropriada para extrair os padrões que refletem os objetivos propostos inicialmente. Exemplos de tarefas clássicas são: Classificação, Descoberta de Regras de Associação, Mineração de Sequências e Mineração de Regras de Exceção.

- Interpretação e Avaliação: última etapa do processo de KDD, responsável por avaliar os resultados obtidos sob diferentes perspectivas (objetivas e subjetivas), a fim de verificar se o resultado do processo é válido, útil e interessante.

Figura 8 - O processo de KDD

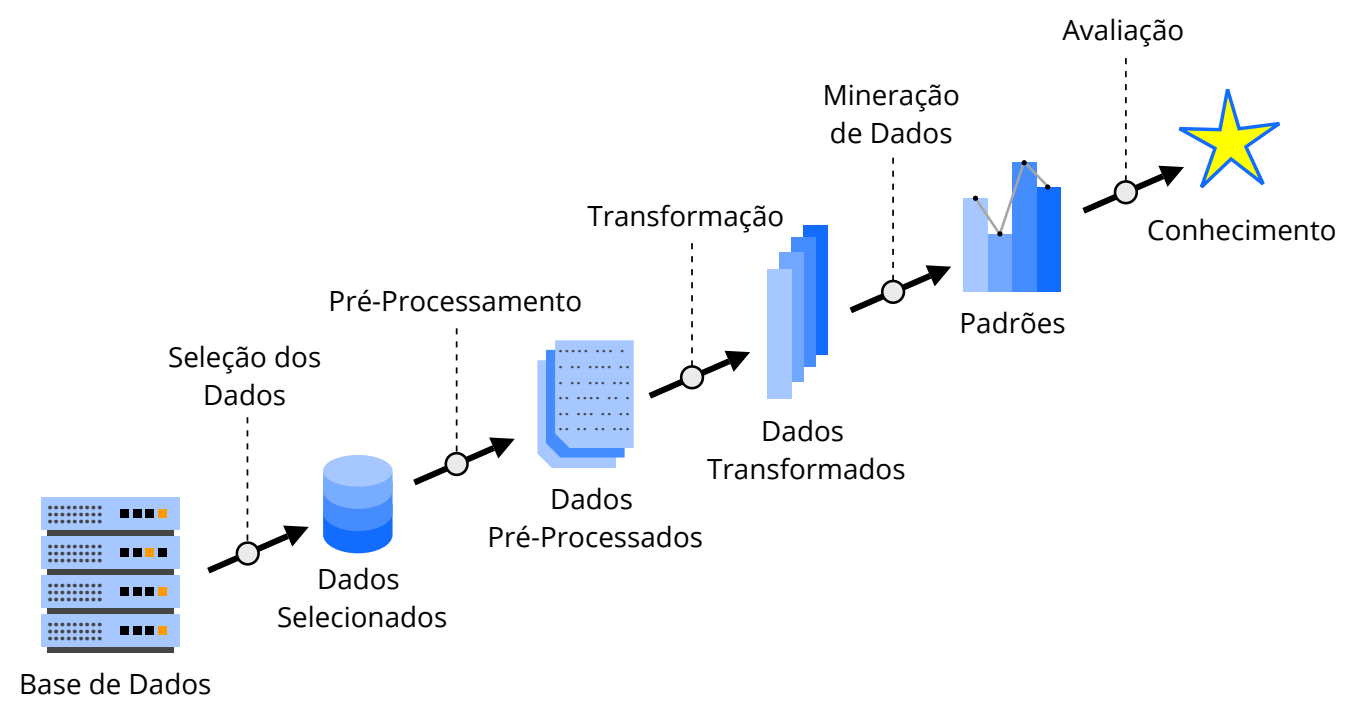

Fonte: Adaptada de Fayyad e Uthurusamy (1996).

Como o processo de KDD é iterativo e interativo, existe a possibilidade de retomar qualquer uma das etapas anteriores se os resultados não forem satisfatórios e condizentes com o esperado. Dentre as tarefas de Mineração de Dados, o interesse deste trabalho é nas tarefas de Descoberta de Regras de Associação, Mineração de Sequências e Mineração de Regras de Exceção, que serão detalhadas a seguir.

\subsection{Descoberta de Regras de Associação}

A tarefa de Descoberta de Regras de Associação (AGRAWAL; IMIELINSKI; SWAMI, 1993) fundamenta-se em encontrar relacionamentos frequentes e confiáveis nas bases de dados. Neste contexto, uma base de dados é definida como uma coleção de transações, cada uma 
composta por um conjunto de itens. Assim, para descobrir uma regra de associação é preciso encontrar itens que ocasionam a presença de outros em uma mesma transação.

Utilizada, em princípio, em análise de cestas de compras para identificar eventuais padrões de consumo, esta tarefa tornou-se popular em outros contextos por expressar de maneira simples e intuitiva os relacionamentos de interesse das aplicações. A Tabela 1 ilustra um cenário de análise de cestas de compras, onde cada linha representa uma transação que contém um identificador único denominado TID e um conjunto de itens comprados por determinado cliente.

Tabela 1 - Transações de Cestas de Compras

\begin{tabular}{c|c}
\hline$T I D$ & Itens \\
\hline 1 & $\{$ Pão, Leite\} \\
\hline 2 & $\{$ Leite, Manteiga, Ovos $\}$ \\
\hline 3 & $\{$ Leite, Açúcar, Manteiga, Cerveja\} \\
\hline 4 & $\{$ Açúcar, Leite, Manteiga $\}$ \\
\hline 5 & $\{$ Pão, Leite, Manteiga \\
\hline
\end{tabular}

Um exemplo de regra de associação extraída deste cenário é: "a maioria das transações que possuem leite também possuem manteiga". Varejistas podem usar este tipo de regra para estudar o perfil de compra de seus clientes e potencializar, por exemplo, a implantação de estratégias personalizadas de promoções e vendas.

Além do cenário de cestas de compras, regras de associação podem ser aplicadas em outros domínios, como agrometeorologia. Neste contexto, padrões de associação podem revelar conexões importantes entre clima e agricultura, permitindo uma melhor compreensão, por exemplo, do impacto de diferentes condições climáticas em culturas agrícolas.

\section{Definições}

Considere um conjunto de itens $I$ e um banco de dados $D B$ composto por um conjunto de transações $T$. Cada transação contém um subconjunto de itens de $I$. Em análise de regras de associação, adota-se a terminologia de itemset para a coleção de um ou mais itens. Ainda, um conjunto de $k$ itens denomina-se $k$-itemset. Por exemplo, \{Leite,Manteiga $\}$ é um 2-itemset.

Regras de associação são implicações no formato $X \rightarrow Y$ que relacionam a presença dos itemsets $X$ e $Y$ em transações de $D B$, em que $X \cap Y=\varnothing$ e $X, Y \neq \varnothing$. Esta regra pode ser traduzida da seguinte maneira: "se $X$ então $Y$ " e indica que quando $X$ ocorre, $Y$ também tende a ocorrer. Além disso, $X$ é chamado de antecedente e $Y$ é chamado de consequente da regra.

O interesse da tarefa de Descoberta de Regras de Associação está em minerar padrões que não são meramente ocasionais. Para isso, utiliza-se medidas objetivas que selecionam regras interessantes dentre as muitas que podem ser descobertas por um algoritmo de Descoberta de Regras de Associação. O suporte e a confiança são exemplos clássicos de medidas de interesse 
objetivas. O suporte (sup) de $X \rightarrow Y$ determina a frequência que o itemset ocorre, considerando o total de transações do banco de dados $(T)$, como mostra a Equação 3.1:

$$
\sup (X \rightarrow Y)=\frac{\operatorname{freq}(X \cup Y)}{T}
$$

A confiança (conf) de $X \rightarrow Y$ mede a probabilidade do consequente da regra ocorrer em transações que já contêm o antecedente, como representado na Equação 3.2:

$$
\operatorname{conf}(X \rightarrow Y)=\frac{\operatorname{freq}(X \cup Y)}{\text { freq }(X)}
$$

Dados os thresholds de suporte (minsup) e confiança (minconf) previamente determinados, pode-se dizer que $X \rightarrow Y$ é frequente se $\sup (X \rightarrow Y) \geq$ minsup. Analogamente, $X \rightarrow Y$ é dita confiável se $\operatorname{con} f(X \rightarrow Y) \geq \operatorname{minconf}$. Além disso, uma regra $X \rightarrow Y$ denomina-se forte se for frequente e confiável.

Uma alternativa às medidas de suporte e confiança foi proposta em Berzal et al. (2002), em que a importância da regra é mensurada pelo fator de certeza. O fator de certeza $(f c)$ propõe resolver algumas das limitações da confiança. Em particular, a combinação de suporte e fator de certeza reduz significativamente o número de regras geradas, filtrando aquelas que correspondem à independência estatística e dependência positiva ou negativa. Como resultado, as regras obtidas são mais fortes do que as geradas por meio de suporte e confiança.

O fator de certeza varia de - 1 a 1 e mede como a probabilidade de $Y$ estar em uma transação altera quando sabe-se que $X$ também está. Valores positivos indicam que a probabilidade aumenta, negativos informam que diminui e 0 indica que não há mudança. Desse modo, $X \rightarrow Y$ é dita certa se $f c(X \rightarrow Y) \geq \min f c$, em que $\min f c$ é o threshold mínimo para fator de certeza previamente definido. A Equação 3.3 define o fator de certeza de $X \rightarrow Y$.

$$
f c(X \rightarrow Y) \begin{cases}\frac{\operatorname{conf}(X \rightarrow Y)-\sup (Y)}{1-\sup (Y)} & \text { se } \operatorname{conf}(X \rightarrow Y)>\sup (Y) \\ \frac{\operatorname{conf}(X \rightarrow Y)-\sup (Y)}{\sup (Y)} & \text { se } \operatorname{conf}(X \rightarrow Y)<\sup (Y) \\ 0 & \text { caso contrário }\end{cases}
$$

Na literatura da área, existem diversos algoritmos para Descoberta de Regras de Associação, como Apriori (AGRAWAL; IMIELINSKI; SWAMI, 1993), ECLAT (ZAKI, 2000) que armazena para cada item a lista de transações que ele ocorre (formato vertical) e SART (CANO et al., 2012), que utiliza conceitos mais complexos como a projeção do banco de dados. Dentre eles, Apriori é considerado o grande precursor da área e devido à sua simplicidade é um dos algoritmos mais conhecidos e utilizados em Descoberta de Regras de Associação. 


\subsubsection{O algoritmo Apriori}

Apriori (AGRAWAL; IMIELINSKI; SWAMI, 1993) tem como objetivo descobrir regras fortes em um banco de dados (regras que satisfazem os thresholds de suporte e confiança prédefinidos). Segundo os autores, a premissa de minerar regras com essas propriedades permite dividir o problema de descoberta de regras de associação em duas etapas principais: $(I)$ geração de candidatos e (II) validação. A fase crítica do problema de associação é a etapa de geração de candidatos, pois consiste em um processo de natureza combinatorial.

Na primeira iteração da etapa de geração de candidatos, geram-se itemsets de tamanho 1 por meio da varredura completa do banco de dados. Para cada itemset candidato, calcula-se seu valor de suporte e verifica-se se atende o limiar de suporte mínimo informado, descartando aqueles cujo sup $<$ minsup. As próximas iterações utilizam o conjunto de $k$-itemsets encontrado na iteração anterior para formar um $k+1$-itemset candidato. Este processo é repetido até que nenhum $k+1$ itemset frequente possa ser gerado. Por fim, a etapa de validação é responsável por validar os itemsets frequentes, selecionando aqueles cuja conf $\geq \operatorname{minconf}$.

Apriori assume que se um conjunto de itens é frequente, então todos os seus subconjuntos também serão (princípio Apriori). Este princípio é válido devido à propriedade anti-monotônica da medida de suporte: "o suporte de um itemset nunca excede o suporte de seus subconjuntos". O inverso desta propriedade também é aplicável: "se um itemset não é frequente não é necessário gerar quaisquer superconjuntos dele, pois eles também não serão frequentes".

Para exemplificar, suponha que $\{a, b, c\}$ é um itemset frequente. Assim, pelo princípio Apriori, qualquer transação que contenha $\{a, b, c\}$ deve conter os subconjuntos $\{a\},\{b\},\{c\}$, $\{a, b\},\{a, c\}$, e $\{b, c\}$, que também são frequentes. De modo inverso, se $\{a, b\}$ é infrequente, então todos os seus superconjuntos devem ser infrequentes também. Os itemsets $\{a, b, c\} \mathrm{e}$ $\{a, b, c, d\}$, por exemplo, podem ser podados imediatamente devido à baixa frequência de $\{a, b\}$.

\subsection{Mineração de Sequências}

A tarefa de Descoberta de Regras de Associação, descrita na Seção 3.1, atende a necessidade de se obter conjuntos de itens que aparecem com frequência em uma mesma transação. Apesar disso, em determinadas aplicações a ordem de ocorrência dos itens é importante e enriquece semanticamente o contexto do problema. Nesses casos, a Mineração de Sequências é mais apropriada por considerar a informação temporal no processo de descoberta de conhecimento.

O problema da Mineração de Sequências foi introduzido por Agrawal e Srikant (1995) com o propósito de encontrar sequências de itens que ocorrem ordenados como padrões. Assim, padrões sequenciais podem ser descritos como: "quando $X$ ocorre, $Y$ ocorre após certo tempo".

No mercado varejista, a descoberta de padrões sequenciais favorece a implantação de estratégias antecipadas de vendas. Uma vez que o padrão de compra do cliente é conhecido, 
pode-se direcionar promoções específicas antes dele adquirir o outro produto descoberto pelo padrão sequencial. Um exemplo de padrão neste contexto é ilustrado na Figura 9: "consumidores que compram notebook comprarão um headphone dois meses depois".

Figura 9 - Exemplo de padrão sequencial no mercado varejista

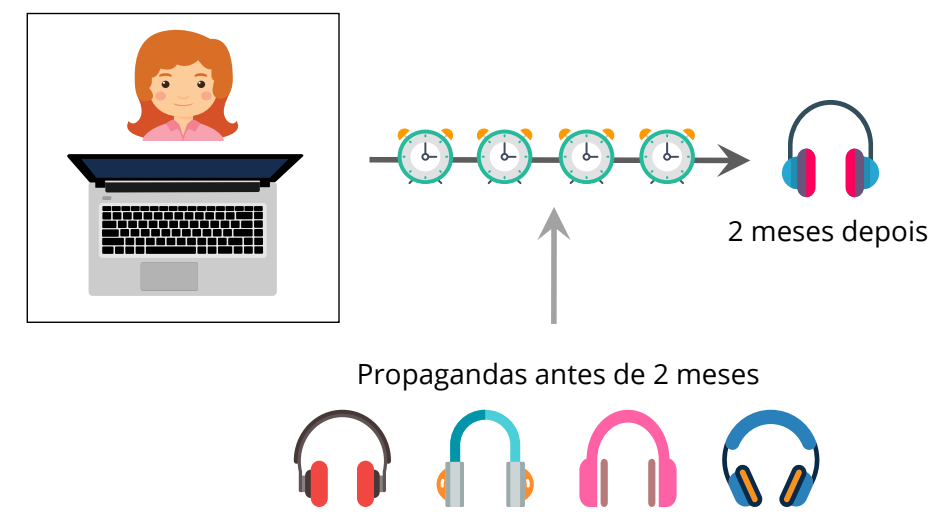

Fonte: Elaborada pelo autor.

\section{Definições}

Cada transação em um banco de dados de sequências corresponde à ocorrência de uma sequência em certo instante de tempo. Uma sequência consiste em uma lista ordenada de itemsets. Uma sequência, portanto, é denotada por $\operatorname{Seq}=<\operatorname{Se} q_{1}, \operatorname{Se} q_{2}, \ldots, \operatorname{Se} q_{n}>$, onde $\operatorname{Seq} q_{i}$ é um itemset. Uma sequência $\left\langle a_{1}, a_{2}, \ldots, a_{m}\right\rangle$ está contida em uma sequência $\left\langle b_{1}, b_{2}, \ldots, b_{n}\right\rangle$, se existirem inteiros $i_{1}<i_{2}<\ldots<i_{m}$ tal que $a_{1} \subset b_{i 1}, a_{2} \subset b_{i 2}, \ldots, a_{m} \subset b_{i m}$.

De modo geral, as sequências podem ser organizadas nos formatos horizontal e vertical. O formato horizontal é considerado o tipo padrão de representação para diversas aplicações. Os dados são organizados por transação e cada informação é apresentada em colunas. Na maioria dos casos, as informações das transações são: o identificador único da transação (TID), o instante de tempo que ela ocorreu e a sequência de itemsets, como apresentado na Tabela 2.

Tabela 2 - Exemplo de Banco de Dados em Formato Horizontal

\begin{tabular}{c|c|c}
\hline$T I D$ & Tempo & Itemsets \\
\hline 1 & $10 / 04 / 2019$ & $<A, B>$ \\
\hline 2 & $12 / 04 / 2019$ & $<A>$ \\
\hline 3 & $08 / 05 / 2019$ & $\langle B, C>$ \\
\hline 4 & $18 / 05 / 2019$ & $<A>$ \\
\hline 5 & $23 / 07 / 2019$ & $<C>$ \\
\hline 6 & $31 / 07 / 2019$ & $<B>$ \\
\hline 7 & $01 / 08 / 2019$ & $<C>$ \\
\hline
\end{tabular}

Fonte: Elaborada pelo autor. 
Um dos problemas do formato horizontal é a necessidade de efetuar a varredura completa do banco de dados para calcular o suporte de cada itemset, o que não ocorre no formato vertical. No formato vertical, cada itemset é associado à lista de transações em que ocorre, como mostra a Tabela 3. Ao contrário do formato horizontal não é necessário efetuar a varredura completa no banco de dados para calcular o suporte de um itemset.

Como cada lista de transações possui todas as informações relevantes sobre determinado itemset, pode-se calcular o suporte de um itemset pelo número de transações que compõem a lista. Para calcular o suporte de dois itens, basta realizar, através de uma operação simples de intersecção, a contagem das transações contidas tanto em um quanto em outro item.

Tabela 3 - Exemplo de Banco de Dados em Formato Vertical

\begin{tabular}{c|c|c|c|c|c}
\hline \multicolumn{2}{c|}{$A$} & \multicolumn{2}{c|}{$B$} & \multicolumn{2}{c}{$C$} \\
\hline$T I D$ & Tempo & TID & Tempo & TID & Tempo \\
\hline 1 & $10 / 04 / 2019$ & 1 & $10 / 04 / 2019$ & 3 & $08 / 05 / 2019$ \\
\hline 2 & $12 / 04 / 2019$ & 3 & $08 / 05 / 2019$ & 5 & $23 / 07 / 2019$ \\
\hline 4 & $18 / 05 / 2019$ & 6 & $31 / 07 / 2019$ & 7 & $01 / 08 / 2019$ \\
\hline
\end{tabular}

Na literatura da área, são propostos diversos algoritmos para Mineração de Sequências. Apesar de terem o mesmo objetivo, esses algoritmos lidam de maneiras distintas com o banco de dados, seguindo uma de três abordagens principais:

- Algoritmos de formato horizontal: baseiam-se no Apriori e são aplicados em bancos de dados de formato horizontal. AprioriAll (AGRAWAL; SRIKANT, 1995) e GSP (SRIKANT; AGRAWAL, 1996) são exemplos de algoritmos que seguem esta abordagem.

- Algoritmos de formato vertical: mineram bancos de dados em formato vertical. SPADE (ZAKI, 2001) e CM-SPADE (FOURNIER-VIGER et al., 2014), são exemplos de algoritmos que utilizam esta abordagem.

- Algoritmos baseados em padrão de crescimento: utilizam itens frequentes para projetar recursivamente o banco de dados de sequências em bancos de dados menores. FP-Growth (HAN; PEI; YIN, 2000) e Prefix-Span (PEI et al., 2004) são exemplos de algoritmos que aplicam esta abordagem.

\subsubsection{O algoritmo GSP}

O algoritmo para Mineração de Sequências Generalized Sequential Patterns (GSP) proposto por Srikant e Agrawal (1996) baseia-se no Apriori e, portanto, lida com bancos de dados horizontais. Ao contrário de algoritmos para Descoberta de Regras de Associação, GSP não implementa a etapa de validação. Isso significa que GSP apenas minera sequências frequentes e não estabele relações de causa e consequência entre itemsets. 
A operação básica do algoritmo é descrita a seguir. Na primeira iteração de geração de candidatos determina-se o suporte de cada item. Para o GSP, o suporte é definido pelo número de transações que contêm o item. Ao final desta iteração, o algoritmo sabe quais itens são frequentes e cada um gera uma sequência de tamanho 1. As iterações subsequentes começam com um seed set. O seed set é composto por sequências frequentes encontradas na iteração anterior e é utilizado para gerar novas sequências candidatas. Cada sequência candidata possui um item a mais do que uma sequência do seed set. Este processo é repetido até que não existam mais sequências frequentes ou nenhum candidato possa ser encontrado.

A geração de candidatos é composta ainda pelas fases de junção e poda. Na junção, a sequência $S e q_{1}$ junta-se com $S e q_{2}$ se, retirando-se o primeiro itemset de $S e q_{1}$ e o último de $S e q_{2}$ as sequências permanecerem iguais. Desse modo, cria-se uma nova sequência candidata, $\mathrm{Seq}_{3}$, com a inclusão dos itemsets removidos. A Figura 10 ilustra a fase de junção para as sequências $<(1,2),(3),(5)>\mathrm{e}<(2),(3),(5),(7)>$.

Figura 10 - Junção de sequências

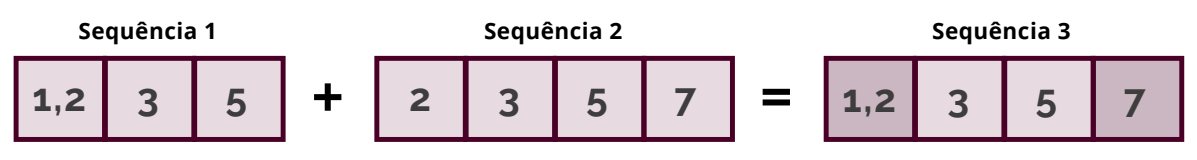

Fonte: Elaborada pelo autor.

A segunda fase da etapa de geração de candidatos é a poda, em que o GSP aplica o princípio Apriori para eliminar sequências candidatas cujo valor de suporte é inferior ao suporte mínimo definido. $\mathrm{O}$ resultado do algoritmo, por fim, são as sequências frequentes mineradas.

\subsubsection{O algoritmo SPADE}

O algoritmo Sequential Pattern Discovery using Equivalent classes (SPADE) (ZAKI, 2001), lida com bancos de dados em formato vertical. Assim, cada itemset é associado à lista de transações que ocorre (também denominada id-list), juntamente com os respectivos instantes de tempo. SPADE também não implementa a etapa de validação e, portanto, apenas minera sequências e não estabele relações de causa e consequência entre itemsets.

Diferente do GSP que percorre o banco a cada iteração, SPADE implementa técnicas de busca em reticulado para decompor o espaço de busca original (reticulado) em espaços menores, permitindo que eles sejam processados de modo independente na memória principal. As sequências possuem um identificador único $S I D$ e cada itemset em uma sequência é representado por um EID. O suporte de uma sequência é dado pelo número de transações que a contêm.

A operação básica do $S P A D E$ é descrita a seguir. Inicialmente o algoritmo percorre o banco vertical e procura sequências frequentes de tamanho 1. Para cada itemset, percorre-se sua 
id-list, incrementando o contador de suporte para cada SID encontrado. Para gerar sequências de tamanho 2, converte-se a parte correspondente às id-lists em um banco de dados horizontal. Este banco é obtido como segue: para cada itemset frequente it, considera-se o par $\left(S I D_{j}, E I D_{j}\right)$ de sua $i d$-list e adiciona-se $\left(i t, E I D_{j}\right)$ na linha do banco horizontal correspondente a $S I D_{j}$. O conjunto 2-sequências frequentes é gerado a partir deste banco horizontal, como descrito a seguir.

Cria-se uma matriz $f \times f$, onde $f$ representa o número de itemsets frequentes, para armazenar na posição $i, j$, tal que $i \leq f$ e $j \leq f$, o contador de suporte para a 2-sequência. A cada 2 -sequência frequente encontrada, atualiza-se seu contador de suporte na matriz de contadores criada. As demais $k$-sequências, $(k>2)$, são obtidas por meio de junções de id-lists sobre as $(k-1)$-sequências já encontradas. Dependendo dos pares de $(k-1)$-sequências utilizados na junção, existem três possibilidades de resultado para uma $k$-sequência candidata:

- Itemset com itemset: Para a junção dos itemsets $(a, b)$ com os itemsets $(a, d)$, por exemplo, existe apenas uma possibilidade de resultado, que é o itemset $(a, b, d)$.

- Itemset com sequência: Para a junção do itemset $(a, b)$ com a sequência $(a),(c)$, por exemplo, existe apenas uma possibilidade de resultado, que é a sequência $(a, b),(c)$.

- Sequência com sequência: A junção da sequência $(a),(b)$ com a sequência $(a),(f)$, por exemplo, resulta em três possibilidades de resultado: um novo evento $(a),(b, f)$ e duas novas sequências $(a),(b),(f)$ e $(a),(f),(b)$.

Em relação ao suporte de uma $k$-sequência candidata, o mesmo é calculado efetuando-se a junção das $i d$-lists relativas ao par de $(k-1)$-sequências utilizadas na obtenção da $k$-sequência candidata. De posse da id-list para a $k$-sequência candidata, seu suporte é facilmente calculado contando-se os SID distintos da id-list.

\subsubsection{O algoritmo PrefixSpan}

Prefix-Projected Sequential Pattern Growth (Prefix-Span) (PEI et al., 2004) é um algoritmo de Mineração de Sequências mais eficiente que GSP e $S P A D E$, sendo capaz de lidar com grandes bases de dados. As propostas de melhoria deste algoritmo estão, principalmente, na diminuição do banco de dados a ser varrido e também no número de candidatos gerados. Assim como GSP e SPADE, Prefix-Span não implementa a etapa de validação e, consequentemente, não estabelece relações de causa e consequência.

Diferentemente de algoritmos que seguem a técnica Apriori, Prefix-Span baseia-se no conceito de pattern growth, o qual não requer a etapa de geração de candidatos, necessitando apenas da projeção do banco de dados de acordo com seu prefixo. 
A seguir, são definidos conceitos básicos do Prefix-Span. Dadas duas sequências $S e q=<$ $s e q_{1}, s e q_{2}, \ldots, s e q_{n}>$ e $S e q^{\prime}=<s e q_{1}^{\prime}, s e q_{2}^{\prime}, \ldots, s e q_{m}^{\prime}>$, tal que $m \leq n$, a sequência $S e q^{\prime}$ é dita prefixo de $S e q$ se, e somente se:

1. $s e q_{i}^{\prime}=s e q_{i}$, para $i \leq m-1$.

2. $\operatorname{seq}_{m}^{\prime} \subset \operatorname{seq}$.

3. todos os itemsets em $\left(s e q_{m}-s e q_{m}^{\prime}\right)$ são maiores do que os itemsets de $s e q_{m}$ (seguindo a ordem considerada nos itens).

O sufixo de $S e q$ em relação ao prefixo $S e q^{\prime}$ é a sequência $\gamma=<s e q_{m}^{\prime \prime}, s e q_{m+1}, \ldots, s e q_{n}>$, em que $s e q_{m}^{\prime \prime}=s e q_{m}-s e q_{m}^{\prime}$. Nos casos em que o itemset $s e q_{m}^{\prime \prime}$ não é vazio, costuma-se denotar o sufixo $\gamma$ por $<_{-} s e q_{m}^{\prime \prime}, s e q_{m+1}, \ldots, s e q_{n}>$, para indicar que o sufixo começa no interior de um itemset de Seq. Seja Seq $=<(a),(a, b),(a, c),(d),(c, f)>$, conforme ilustrado na Figura 11. As sequências: $<(a)>$, $<(a),(a)>$ e $<(a),(a, b)>$ são exemplos de prefixos de Seq. O sufixo de $S e q$ com relação a $<(a),(a, b)>$ é $\gamma=<\left(\_c\right),(a, c),(d),(c, f)>$.

Figura 11 - Exemplos de prefixos

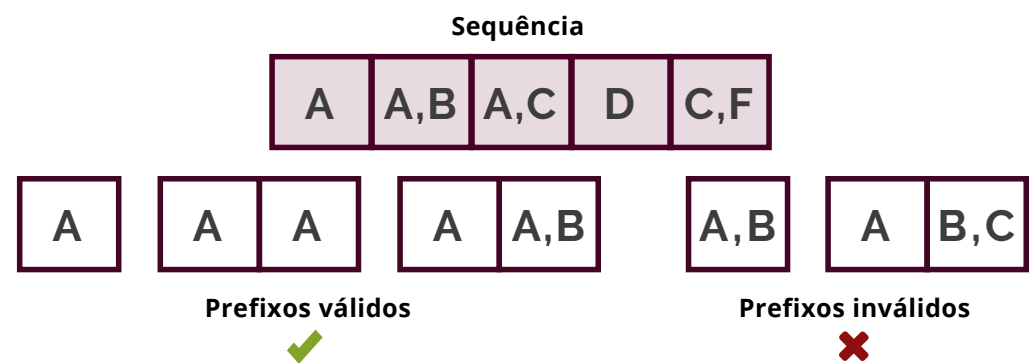

Fonte: Elaborada pelo autor.

Seja $D B$ um banco de dados e $d$ uma sequência deste banco de dados, $\alpha$ é um padrão sequencial, tal que $\alpha=<a_{1}, a_{2}, \ldots, a_{k}>$. Nesse contexto, $d^{\prime}$ corresponde à primeira ocorrência de $\alpha$ em $D B$. Por exemplo, se $D B=<(a, b),(c, d),(e)>$ e $\alpha=<(b),(c)>$, então $d^{\prime}=<(a, b),(c, d)>$. A projeção de $d^{\prime}$ com relação ao prefixo $\alpha$ é denotada por $(\operatorname{proj}(d, \alpha))$ é definida como sendo o sufixo de $d^{\prime}$ com relação ao prefixo $\alpha$. Considerando o exemplo citado anteriormente, $\operatorname{proj}\left(d^{\prime}, \alpha\right)=<(d),(e)>$.

A operação básica do Prefix-Span é descrita a seguir. Inicialmente, lê-se o banco de dados para encontrar sequências frequentes de tamanho 1. A saída do algoritmo é dada pelo conjunto de sequências frequentes e consiste na união disjunta de $p$ subconjuntos.

Para minerar cada conjunto, considera-se o banco de dados projetado $\operatorname{proj}(D B, \alpha)$. Este banco de dados é formado por todos os sufixos de sequências de $D B$ com relação ao prefixo 
$\alpha$. Vale ressaltar que para cada sequência $S e q$ de $D B$, caso $s e q_{i}$ ocorra diversas vezes, apenas considera-se o sufixo correspondente à primeira ocorrência de $\alpha_{i}$ em $D B$.

Para cada $\left\langle\alpha_{i}>\right.$ percorre-se o banco de dados projetado para encontrar os itemsets frequentes e o respectivo suporte. A partir dos itens frequentes, obtém-se padrões frequentes de tamanho 2, com prefixo $<\alpha_{i}>$, juntamente com seu valor de suporte.

Desse modo, cada conjunto que possui os padrões prefixados por $<\alpha_{i}>$ é subdividido em subconjuntos disjuntos que correspondem a prefixos dados por cada 2-sequência frequente encontrada. Por fim, cada banco de dados é novamente projetado e percorrido para encontrar sequências de tamanho 3. Assim, recursivamente todas sequências serão produzidas.

\subsection{Mineração de Regras de Exceção}

Embora tarefas de Descoberta de Regras de Associação e Mineração de Sequências sejam úteis para encontrar tendências nos dados, tornam-se falhas quando o interesse é descobrir padrões incomuns e pouco frequentes. Existem poucas abordagens na literatura que lidam com a extração de padrões pouco frequentes, sendo esta uma área de pesquisa pouco explorada.

Neste contexto, o foco deste trabalho está na descoberta de padrões que, embora ocorram com pouca frequência, possuem consequências potencialmente críticas em diversas aplicações. Esta classe de padrão denomina-se regras de exceção (SUZUKI, 1996; HUSSAIN et al., 2000).

Regras de exceção são definidas como padrões que contradizem o comportamento usual. Especificamente, para descobrir uma regra de exceção é preciso identificar o agente que modifica o consequente esperado de uma regra forte. Um exemplo de regra de exceção em medicina é: "o uso de antibióticos em pacientes com estafilococo pode levar à morte". Esta regra contradiz o comportamento usual representado pela seguinte regra forte: "com o uso de antibióticos, o paciente tende a se recuperar", e o agente responsável pela alteração do consequente da regra é o estafilococo. A Figura 12 ilustra este exemplo, ressaltando as regras forte e de exceção.

Figura 12 - Exemplo de regra de exceção em medicina

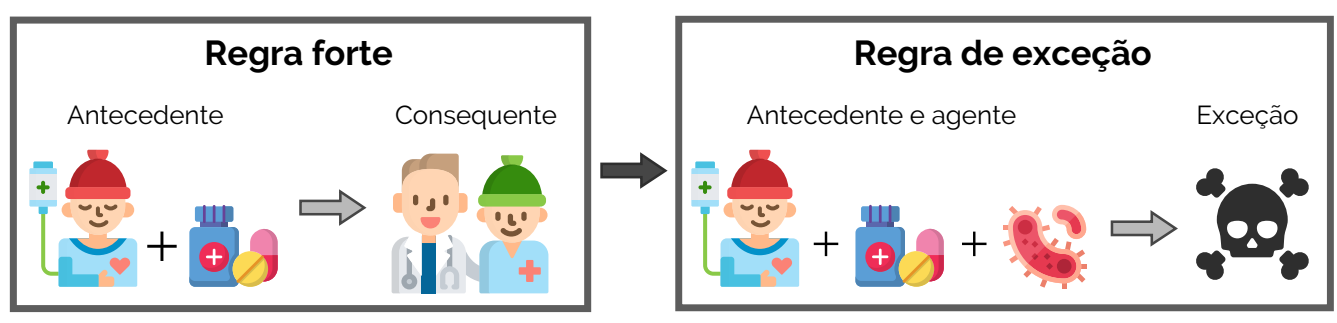

Fonte: Elaborada pelo autor.

A mineração de ambas regras explica os agentes que perturbam comportamentos usuais. 
Como resultado, ações prévias de controle podem ser implementadas em contextos em que agentes inesperados trazem consequências críticas. No exemplo, uma ação de controle prévia para minimizar a probabilidade do paciente contrair a bactéria estafilococo é manter a higiene do paciente no ambiente hospitalar em condições adequadas.

\section{Definições}

Em termos gerais, o tipo de conhecimento descoberto com regras de exceção pode ser descrito como: " $X$ fortemente implica $Y$ (e não $E$ ). Mas, em conjunto com $E, X$ não implica $Y$ ". Trabalhos precursores neste tópico de pesquisa são apresentados por Suzuki (1996) e Hussain et al. (2000) e são explicados a seguir. De acordo com Suzuki (1996), uma regra de exceção é formalmente definida como:

$$
\begin{gathered}
X \rightarrow Y \text { (alto suporte e alta confiança - regra forte). } \\
X \wedge E \rightarrow \neg Y \text { (baixo suporte e alta confiança - regra de exceção). } \\
X \nrightarrow E \text { (alto suporte e alta confiança - regra de referência). }
\end{gathered}
$$

$X \rightarrow Y$ é uma regra forte e, portanto, indica um comportamento usual. $X \wedge E \rightarrow \neg Y$ é uma regra de exceção e mostra que a presença do agente $E$ modificou o consequente esperado da regra forte. $X \nrightarrow E$ é uma regra de referência e determina que o antecedente não deve associar-se com o agente causador da exceção. Retomando o exemplo do estafilococo, uma regra de referência é: "com o uso de antibióticos, o paciente não adquire a bactéria estafilococo".

Uma definição similar é apresentada por Hussain et al. (2000). A diferença está na regra de referência, em que o agente causador da exceção pode influenciar no comportamento inesperado $(E \rightarrow \neg Y)$. Um exemplo de regra de referência para esta definição é: "apesar do uso de antibióticos, o paciente pode adquirir a bactéria estafilococo".

$X \rightarrow Y$ (alto suporte e alta confiança - regra forte).

$X \wedge E \rightarrow \neg Y$ (baixo suporte e alta confiança - regra de exceção).

$X \rightarrow \neg E$ (baixo suporte or baixa confiança - regra de referência).

Definições alternativas às precursoras não utilizam as três regras (forte, de exceção e referência), como apresentado em Daly e Taniar (2008). Tal abordagem fundamenta-se em descobrir comportamento incomum e contraditório, enquanto as abordagens precursoras permitem inferir sobre o agente que causou o comportamento excepcional.

Exception Rule Search Algorithm (ERSA) (DELGADO; RUIZ; SANCHEZ, 2010) baseiase nas premissas apresentadas em Suzuki (1996) e é o atual estado da arte para Mineração de Regras de Exceção. ERSA diferencia-se de seus precursores por não utilizar regras de referência e aplicar fator de certeza ao invés de confiança para validar as regras. Segundo os autores, regras 
de referência podem ser desconsideradas porque não enriquecem semanticamente a definição de exceção. Desse modo, a definição pode ser reformulada como:

$$
X \rightarrow Y \text { (frequente e certa - regra forte). }
$$

$E \rightarrow \neg Y$ (certa no domínio do antecedente da regra forte $\left(D_{X}\right)$ - regra de exceção).

Métodos recentes para Mineração de Regras de Exceção baseiam-se em lógica fuzzy. Um exemplo é o algoritmo Fuzzy Exceptional Rule Search Algorithm (FERSA) (RUIZ et al., 2016). Embora seja similar ao ERSA em concepção e implementação, aplica lógica fuzzy para evitar o problema de imprecisão e inconsistência de dados. Dentre os métodos para Mineração de Regras de Exceção apresentados, ERSA é descrito na Seção seguinte por ser o atual estado da arte.

\subsubsection{O algoritmo ERSA}

ERSA assume que exceções são causadas por um único agente e minera regras fortes e respectivas exceções. A operação básica do algoritmo é descrita a seguir. Inicialmente, o banco de dados transacional é convertido em um formato binário para descobrir itemsets frequentes e selecionar regras fortes. Considere um banco de transações $T$, como apresentado na Tabela 4, o mapeamento para um banco de dados binário é descrito a seguir.

Tabela 4 - Exemplo de Banco de Transações

\begin{tabular}{c|c}
\hline Transação 1 & A B \\
\hline Transação 2 & G H F \\
\hline$\ldots$ & $\ldots$ \\
\hline Transação $t^{\prime}$ & A B C \\
\hline
\end{tabular}

Cada tupla do banco de dados binário corresponde a uma transação do conjunto de dados e cada coluna representa um item. Assim, se determinado item ocorre naquela transação, sua coluna recebe o valor 1 , caso contrário recebe 0 , como mostra a Tabela 5 .

Tabela 5 - Mapeamento do Banco de Transações para um Banco Binário

\begin{tabular}{c|c|c|c|c}
\cline { 2 - 5 } & $\mathrm{A}$ & $\mathrm{B}$ & $\ldots$ & $\mathrm{C}$ \\
\hline Transação 1 & 1 & 1 & $\ldots$ & 0 \\
\hline Transação 2 & 0 & 0 & $\ldots$ & 0 \\
\hline$\ldots$ & $\ldots$ & $\ldots$ & $\ldots$ & $\ldots$ \\
\hline Transação $t^{\prime}$ & 1 & 1 & $\ldots$ & 1 \\
\hline
\end{tabular}

ERSA não faz distinção entre regras fortes e infrequentes, mantendo um único conjunto com todas as regras candidatas. Assim, para cada regra forte $X \rightarrow Y$ encontrada, ERSA percorre este conjunto (que tende a ser grande) em busca de possíveis exceções, isto é, outras regras cujo antecedente contenha $X$ e o consequente seja diferente de $Y$. A complexidade computacional do 
ERSA é de ordem exponencial, isto é, $O\left(\operatorname{Tr} l 2^{l}\right)$, onde $T$ é o número de transações do banco de dados, $l$ é a quantidade de itens e $r$ é o número de regras descobertas.

Durante o estudo da literatura realizado neste trabalho, não foi encontrado nenhum método para descobrir regras de exceção causadas por mais de um agente. Retomando o exemplo do estafilococo: embora uma combinação de agentes possa causar a morte do paciente, trabalhos relacionados apenas reconhecem o estafilococo como agente causador. Além disso, tais métodos não consideram temporalidade no processo de descoberta de regras, pois foram projetados para lidar com bases de itemsets.

\subsection{Considerações Finais}

A tarefa de Descoberta de Regras de Associação atende a necessidade de se obter conjuntos de itens que ocorrem com frequência em uma transação, mas pode não ter utilidade em contextos onde a informação temporal é essencial para a semântica do problema. Nesses casos, a Mineração de Sequências é mais apropriada.

De modo geral, algoritmos de Mineração de Sequências procuram por sequências considerando a ordem que os itens ocorrem, mas não estabelecem relações de causa e consequência. Além disso, são pseudo-polinomiais em termos de complexidade (DONG, 2009) e implementam uma medida de suporte pouco discriminatória. Por isso, quando aplicados para minerar sequências pouco frequentes, geram uma quantidade imensa de sequências em tempo infactível.

Baixos valores de suporte expressam padrões infrequentes, que podem ser fundamentais para alguns domínios de aplicação. Métodos clássicos para Mineração de Regras de Exceção não lidam com temporalidade, assumem que exceções são causadas por um único agente e implementam uma medida de suporte pouco seletiva. A existência de tais limitações, motivou

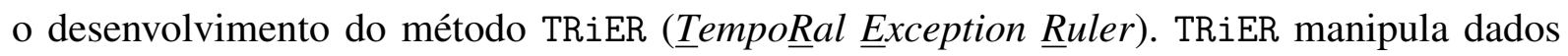
temporais multivariados e descobre padrões temporais e regras de exceção potencialmente causadas por mais de um agente. Além disso, implementa uma medida de suporte mais seletiva que considera o contexto em que o padrão ocorre. 
CAPÍTULO

\section{4}

O MÉTODO TRIER

A Mineração de Regras de Exceção é um tópico de pesquisa pouco explorado, cujos métodos são restritos à manipulação de bancos de dados de itemsets. Considerando a relevância semântica da informação temporal para diversos domínios de aplicação, este projeto de mestrado amplia o estado da arte em mineração de regras de exceção e propõe TRiER (TempoR Ral Exception Ruler): o primeiro método temporal com suporte a dados multivariados.

TRiER amplia o poder exploratório dos métodos propostos na literatura pois além de descobrir conhecimento incomum e o agente causador, revela quanto tempo as consequências demoram para aparecer e os agentes multivariados que podem causá-la. TRiER efetivamente lida com séries temporais univariadas e multivariadas e implementa os conceitos de window e time lag, descritos na Seção 4.2 e Seção 4.3, respectivamente. Em termos gerais, o tipo de conhecimento que TRiER descobre pode ser descrito como:

" $X$ fortemente implica $Y$ após um tempo $t$. Mas $X$ e $E$ (mesmo que $E$ ocorra depois), implica em algo diferente de $Y$ após um tempo $v$ ".

\subsection{Etapas do TRiER}

TRiER pode ser dividido nas etapas de: (1) Mineração de Sequências, (2) Descoberta de Regras e (3) Mineração de Regras de Exceção. Apessar disso, antes de iniciá-las TRiER requer algumas atividades de representação e pré-processamento, dado que séries temporais, de modo geral, correspondem à dados contínuos e podem apresentar valores faltantes e ruídos. A Figura 13 ilustra as etapas do método proposto, que serão detalhadas nas próximas Seções.

TRiER não restringe um método de representação de séries, deixando a critério do usuário a escolha do método que considerar mais apropriado. Vale ressaltar que a natureza dos padrões minerados é infrequente e por isso deve-se escolher uma técnica que mantenha esta característica. 
Figura 13 - TRiER: visão geral

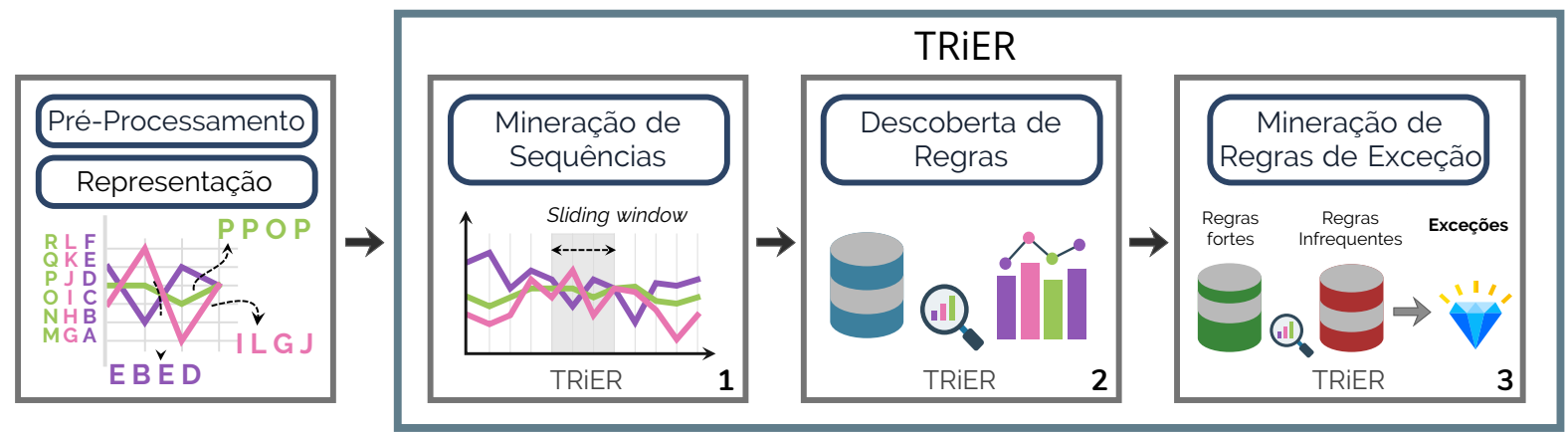

Fonte: Elaborada pelo autor.

TRiER manipula séries temporais de diferentes tamanhos. Especificamente, o método procura por regras fortes e de exceção em um conjunto de séries temporais ( $D$ séries), ao invés de manipular uma única série temporal (geralmente longa). Se determinada variável de uma observação for inexistente, sugere-se aplicar algum método para tratamento de valores faltantes, como a interpolação. Caso contrário, pode ocorrer uma perda de qualidade semântica dos padrões obtidos. A Figura 14 ilustra séries de diferentes tamanhos que podem compor a base de dados e um exemplo de uma observação ausente.

Figura 14 - Exemplo de conjunto de séries temporais para o TRiER

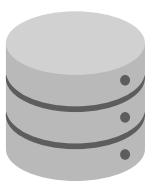

Conjunto de séries

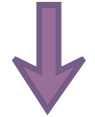

Série 1 A B

Série $2 \quad$ A F

Série 3 N I N S E S P V G F

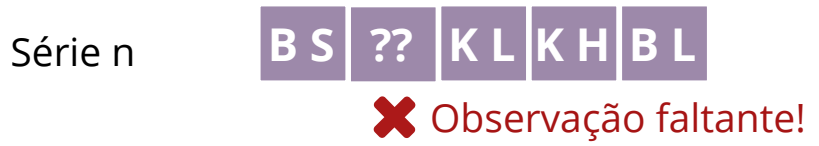

Fonte: Elaborada pelo autor.

Realizadas as atividades de pré-processamento e representação de séries temporais, as etapas do TRiER podem efetivamente ser iniciadas. As etapas são descritas nas próximas Seções. 


\subsection{Mineração de Sequências}

A etapa de Mineração de Sequências tem por objetivo encontrar sequências que irão gerar potenciais regras fortes e de exceção. É a etapa mais custosa, pois consiste em um processo de natureza combinatorial. Para realizá-la, dois parâmetros são aplicados nos dados representados: o tamanho da window $(w)$ e o suporte mínimo para uma sequência ser considerada frequente.

Uma window $(w)$ de uma série $S$ consiste em uma sequência de eventos que ocorre em um intervalo contínuo, iniciando no instante $t_{b}$ e terminando no instante $t_{e}$, de modo que os eventos $t_{b}$ e $t_{e}$ pertençam a $w$. A window é utilizada para restringir o tamanho máximo do padrão sequencial, isto é, o número máximo de observações consecutivas que o padrão pode ter.

Uma das principais contribuições do TRiER é a proposta de uma nova medida de suporte. Isso porque a medida clássica não é designada ao tratamento de séries e quando aplicada neste tipo de dado pode generalizar informações sobre a ocorrência do padrão. Com o intuito de melhor compreender o contexto em que o padrão ocorre, a medida proposta considera dois cenários durante o cálculo de suporte: (1) número de vezes que o padrão ocorre e (2) número de séries temporais que contém o padrão.

A medida clássica não faz distinção do primeiro cenário, pois se um padrão ocorre inúmeras vezes ou apenas uma vez na série, terá a mesma contribuição no cálculo de suporte. Essa suposição representa uma perca semântica, porque ao manipular dados temporais é relevante entender como o padrão ocorre em diferentes instantes de tempo.

O segundo cenário permite entender como o padrão ocorre na totalidade do conjunto de dados. Especificamente, se um padrão ocorre inúmeras vezes em uma única série, mas não ocorre com regularidade no conjunto de dados, pode indicar um comportamento muito específico daquela série e considerá-lo como padrão pode ser incoerente.

A nova medida, portanto, pondera sobre esses cenários para estabelecer uma visão mais abrangente sobre a ocorrência do padrão. A Equação 4.1 formaliza esta medida: $L$ é o número de séries do banco de dados, $P$ é o total de observações do banco de dados (soma da quantidade de observações de cada série que compõe o conjunto de dados), $j$ representa o número de séries em que uma sequência ocorre e $f$ é o número de vezes que uma sequência ocorre.

$$
\sup _{T R E R}=\frac{f}{P} \cdot e^{\left(\frac{j}{L}-1\right)}
$$

A etapa de Mineração de sequências divide-se em três tarefas principais: (1) Geração de sequências com uma variável, (2) Geração de sequências com $n$ variáveis e uma observação e (3) Geração de sequências com $n$ variáveis e $p$ observações, descritas a seguir.

Na primeira tarefa, calcula-se o suporte de cada símbolo do processo de representação, selecionando aqueles cujo suporte é superior ao threshold de minsup $p_{T R E R}$. Na segunda tarefa, geram-se sequências com uma observação e $n$ variáveis. Para gerar uma sequência frequente com 
$n$ variáveis, juntam-se duas sequências frequentes com $n-1$ variáveis, cuja interseção possua $n-2$ variáveis. Como resultado, obtém-se uma sequência com $n$ variáveis.

A Figura 15 ilustra a segunda tarefa, em que são apresentados três casos de junção de sequências. No primeiro deles, juntam-se as sequências $R P$ e $P O$, de tamanho 2, para gerar a sequência $R P O$, com 3 variáveis. No segundo cenário, não é possível juntar as sequências $L G H$ e $L C A$, pois a junção deveria resultar em uma sequência com 4 variáveis. Por fim, ao juntar as sequências $B T A V$ e $A V T C$, obtém-se a sequência $B T A V C$, com 5 variáveis.

Figura 15 - Junção de sequências com uma observação e $n$ variáveis

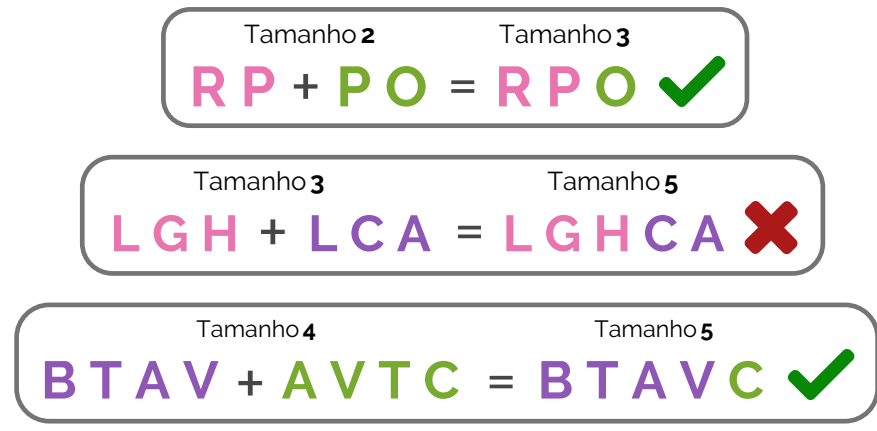

Fonte: Elaborada pelo autor.

$\mathrm{Na}$ terceira etapa, para obter uma sequência com $p$ observações procura-se duas sequências com $p-1$ observações de modo que as primeiras $p-2$ observações de uma sequência coincida com as últimas $p-2$ observações da outra sequência. Juntam-se duas sequências com $p-1$ observações que atendem este requisito para formar uma nova sequência com $p$ observações. Esta tarefa repete-se até o tamanho máximo da window.

A Figura 16 ilustra a terceira tarefa de Mineração de Sequências, em que são apresentados três cenários de junção de sequências. No primeiro deles, juntam-se as sequências $B, T$ e $T, B$ que possuem duas observações, para gerar a sequência $B, T, B$, com três observações.

Figura 16 - Junção de sequências com $p$ observações e $n$ variáveis

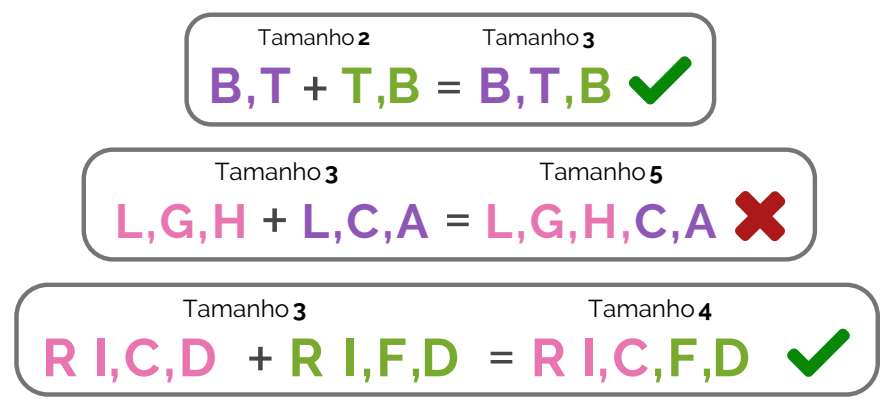

Fonte: Elaborada pelo autor.

No segundo cenário, não é possível juntar as sequências $L, G, H$ e $L, C, A$, pois a junção deveria resultar em uma sequência com quatro observações. Por fim, ao juntar as sequências $R I, C, D$ e $R I, F, D$, obtém-se a sequência $R P, C, F, D$, de tamanho 5. 
O algoritmo 1 sumariza as tarefas da etapa de Mineração de Sequências. Uma vez que as sequências frequentes foram mineradas, inicia-se a etapa de Descoberta de Regras.

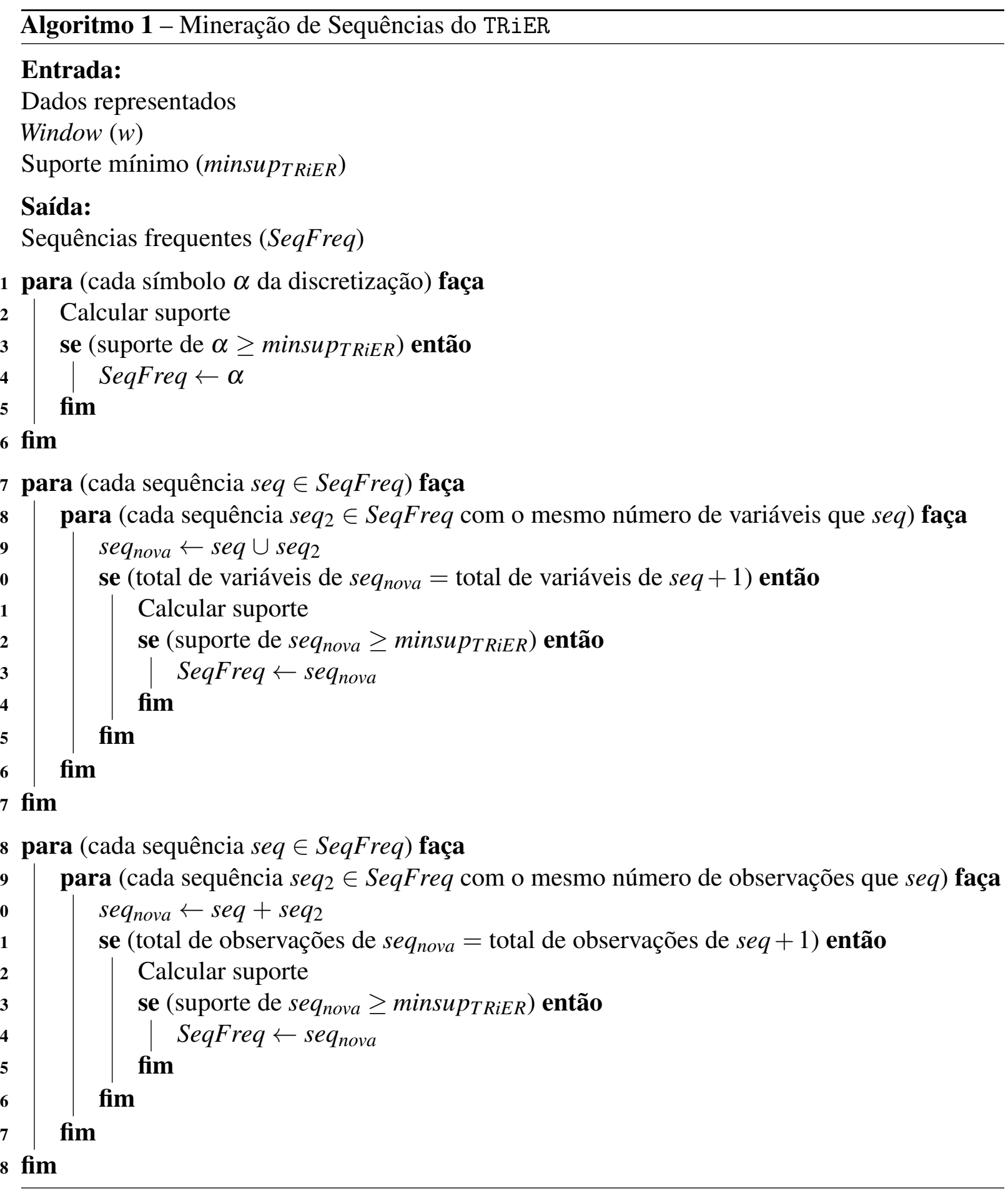

\subsection{Descoberta de Regras}

Esta etapa caracteriza-se por extrair regras fortes e infrequentes com time lag (caso exista), a partir das sequências mineradas na etapa anterior. Time Lag $\left(t_{\text {lag }}\right)$ consiste em um delay, 
em unidades de tempo, entre o início do antecedente e o final do consequente da regra. Time lag segue a granularidade de tempo da série, como dias, meses ou anos.

O funcionamento da etapa de Descoberta de Regras é descrito a seguir. Inicialmente, sequências são analisadas de acordo com as possibilidades de time lag que podem assumir. De uma sequência com $p$ observações é possível extrair regras com time lag variando de 1 a $p-1$. Nos casos em que o time lag é 1, o consequente ocorre na observação subsequente ao antecedente. Por outro lado, se o time lag for $p-1$, o antecedente está contido na primeira observação e o consequente na última observação. Para cada possibilidade de time lag, geram-se as potenciais regras que contêm determinada sequência. A partir da sequência $P S, P L, E, P R$, por exemplo, é possível extrair as seguintes regras:

- $P S, P L, E \rightarrow P R$ (regra com time lag 1 , pois $P R$ ocorre imediatamente após $P S, P L, E$ ).

- $P S, P L \rightarrow P R$ (regra com time lag 2, pois $P R$ ocorre duas unidades de tempo após $P S, P L)$.

- $P S \rightarrow P R$ (regra com time lag 3, pois $P R$ ocorre três unidades de tempo após $P S$ ).

As medidas de validação de regras (confiança e fator de certeza) são compostas pela medida de suporte. Dado que TRiER propõe e implementa uma nova medida de suporte, a confiança e fator de certeza implementados pelo método proposto seguem a nova medida e recebem, respectivamente, as nomenclaturas $\operatorname{con} f_{T R E R}$ e $f c_{T R I E R}$. Nesse contexto, potenciais regras são avaliadas sob os seguintes parâmetros:

(I) Suporte mínimo da regra forte (minsup_str $T R i E R$ ),

(II) Suporte mínimo da regra infrequente (minsup_inf $\left.f_{T R E R}\right)$,

(III) Suporte máximo da regra infrequente $\left(\operatorname{maxsup}_{T R i E R}\right)$,

(IV) Confiança mínima $\left(\right.$ mincon $\left.f_{T R i E R}\right)$,

(V) Fator de certeza mínimo $\left(\operatorname{minc} f_{T R i E R}\right)$.

Uma regra é dita forte se seu suporte-confiança ou suporte-fator de certeza exceder os respectivos thresholds mínimos. Para classificar uma regra como infrequente, TRiER implementa a medida de suporte máximo, assegurando assim que o suporte máximo de uma regra infrequente não exceda o suporte mínimo de uma regra forte. Assim, serão mantidos dois conjuntos distintos para regras: um para regras fortes e outro para infrequentes.

A Figura 17 ilustra a classificação de uma regra entre forte e infrequente. TRiER implementa a medida de fator de certeza como alternativa à confiança, pois ela é mais seletiva e, consequentemente, reduz o número de regras geradas. TRiER também permite a aplicação da 
confiança porque ela compõe o fator de certeza e fundamenta a comparação com outros métodos de Mineração de Regras de Exceção.

Figura 17 - Classificação de regras fortes e infrequentes

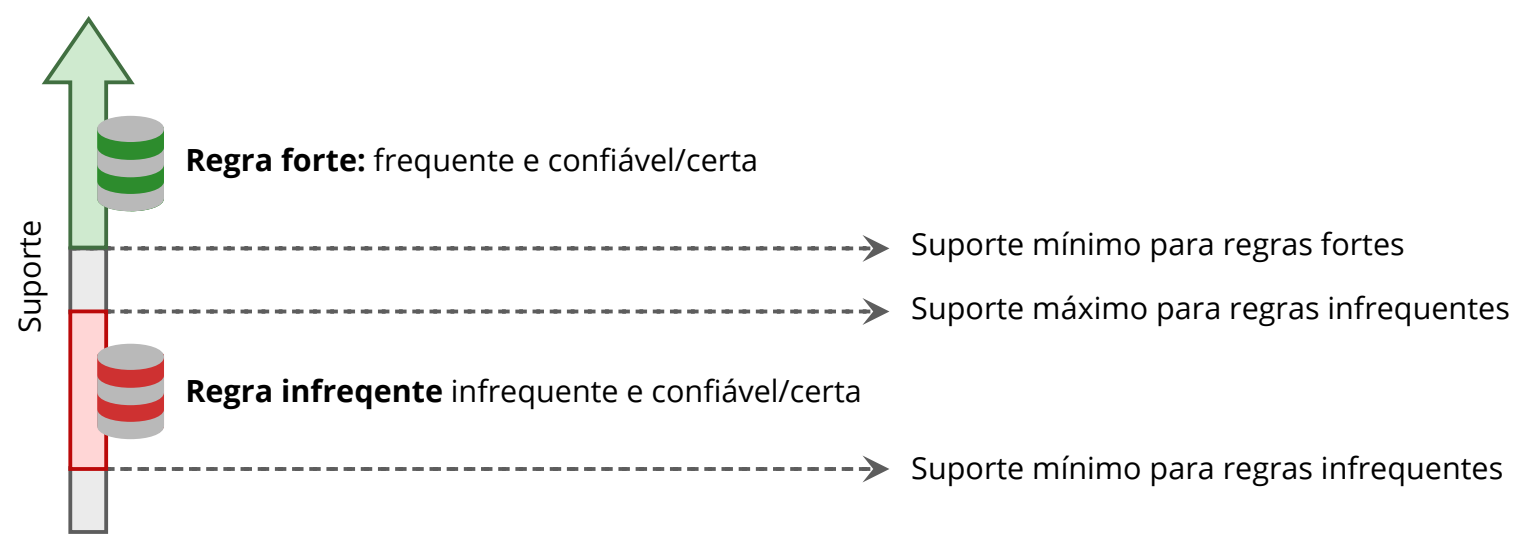

Fonte: Elaborada pelo autor.

\subsection{Mineração de Regras de Exceção}

Uma vez que as regras são classificadas entre fortes e infrequentes, inicia-se a etapa de Mineração de Regras de Exceção, em que uma definição diferente para exceção é proposta. A principal distinção da definição proposta para as definições da literatura é que uma regra de exceção é considerada infrequente. TRiER faz essa distinção porque exceções são naturalmente atípicas e expressam comportamento incomum. Como resultado, exceções são menos frequentes do que o comportamento usual (representado por uma regra forte).

Nos métodos de Mineração de Regras de Exceção da literatura, podem ocorrer casos em que o suporte de uma regra de exceção é maior do que o suporte de uma regra forte, o que semanticamente é incoerente. Para que isso não ocorra, TRiER aplica um threshold de suporte máximo e assegura que o suporte máximo de uma regra de exceção não exceda o suporte mínimo de uma regra forte. Neste trabalho, uma regra de exceção é formalizada como segue:

$X \rightarrow Y$ (frequente e confiável ou frequente e certa - regra forte)

$X \wedge E \rightarrow \neg Y$ (infrequente e confiável ou infrequente e certa - regra de exceção)

Para cada regra forte encontrada, o conjunto de regras infrequentes é analisado para identificar uma regra que atende às seguintes restrições:

- $\mathrm{O}$ antecedente da regra infrequente deve conter o antecedente da regra forte.

- O consequente da regra infrequente não deve conter ou estar incluso no consequente da regra forte. 
A regra infrequente que atender tais restrições constitui uma exceção para a regra forte em questão. É importante ressaltar que o agente causador da exceção pode ocorrer em um lag temporal, contanto que ocorra antes do consequente da regra forte. TRiER também permite que exceções sejam causadas por mais de um agente. $\mathrm{O}$ algoritmo 2 sumariza a operação da etapa de Mineração de Regras de Exceção.

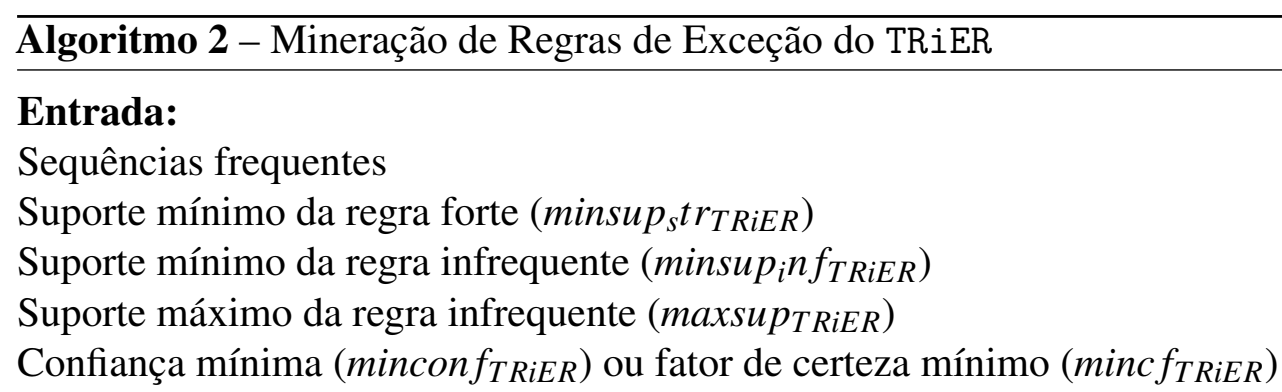

\section{Saída:}

Regras de exceção temporais e suas regras fortes correspondentes

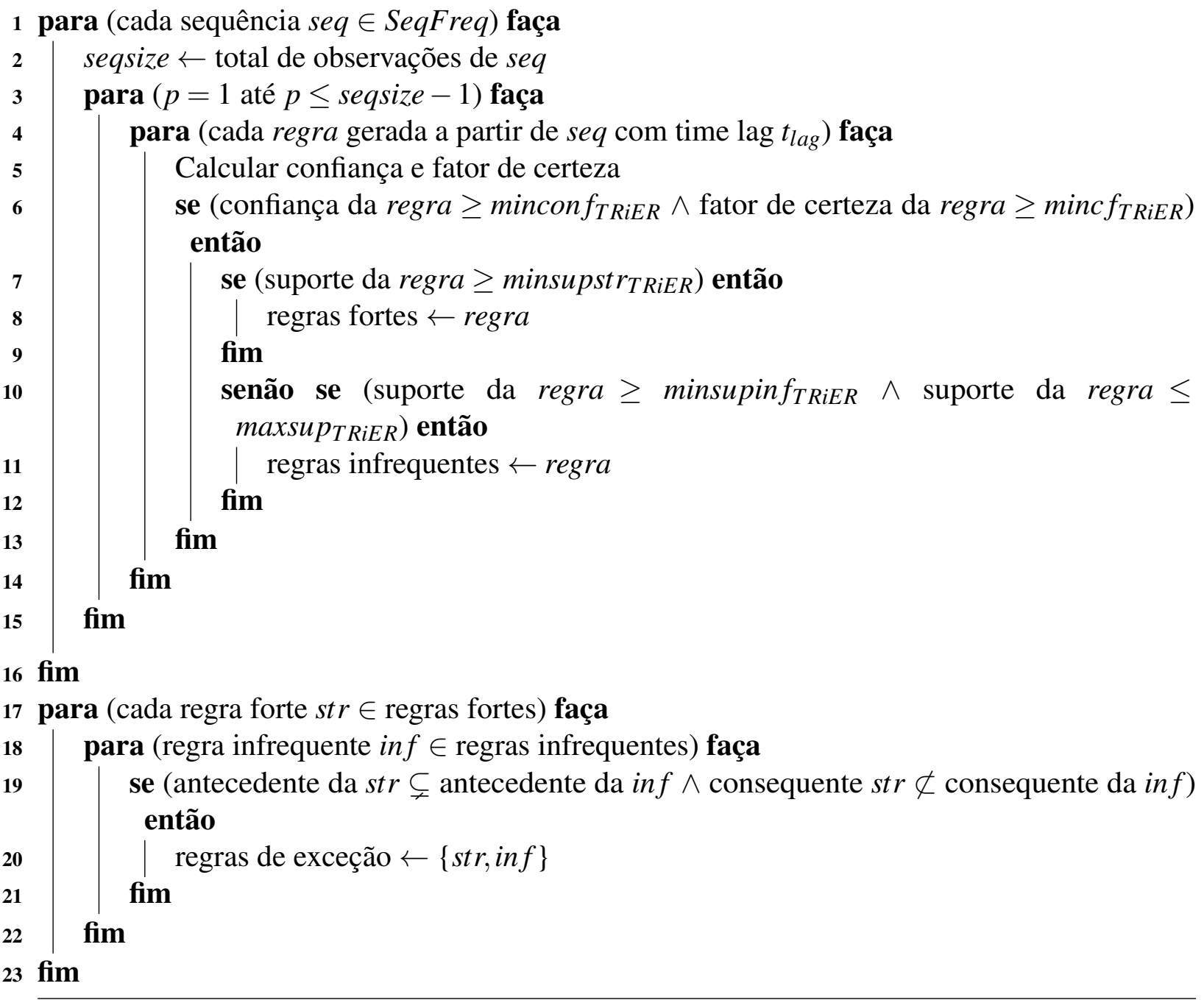




\subsection{Implementação e Complexidade}

Como a etapa de Mineração de Sequências é a mais custosa, esta Seção detalha informações sobre a implementação realizada. TRiER foi implementado em Java e a estratégia desenvolvida para melhorar sua eficiência está relacionada às seguintes estruturas de dados: $(I)$ Hash Map ${ }^{1}$, (II) Hash Set ${ }^{2}$ e (III) Tree Set ${ }^{3}$.

Hash Map é uma estrutura de mapa formada por pares < chave, valor $>$ que permitem recuperar informações com complexidade constante. Hash Set é uma estrutura baseada em conjuntos e, portanto, não armazena elementos duplicados e não estabelece relação de ordem entre eles. As operações básicas desta estrutura possuem complexidade constante. Por fim, Tree Set é uma estrutura que implementa uma árvore rubro-negra e, portanto, ordena os elementos armazenados e possui complexidade logarítmica.

Inicialmente, as séries temporais representadas são armazenadas em duas estruturas de Hash Map, denominadas $I n d_{1}$ e $I n d_{2}$. Em ambas estruturas, as chaves são formadas por observações das séries. Em Ind ${ }_{1}$, o valor de cada chave é um Tree Set composto por pares no formato $(i: j)$, onde a observação que compõe a chave ocorre no instante $i$ da $j$-ésima série do

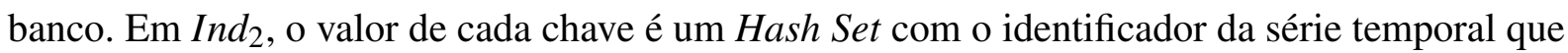
contém a chave em questão, isto é, $j$ pertence ao Hash Set se, e somente se, a observação que compõe a chave ocorre na $j$-ésima série da base de dados.

Feito isso, a etapa de mineração é efetivamente iniciada. As sequências mineradas são armazenadas em um Hash Map, em que a chave é a própria sequência e o valor é o suporte da sequência. As sequências são geradas conforme as três tarefas explicadas na Seção 4.2:

1. Gerar sequências com uma observação e uma variável.

2. Gerar sequências com $p$ observações e uma variável.

3. Gerar sequências com $p$ observações e $n$ variáveis.

Sequências que atendem o threshold de suporte mínimo são armazenadas neste Hash Map. Nas duas primeiras tarefas, o suporte é calculado da seguinte maneira. Para cada sequência candidata, percorre-se $I n d_{1}$ procurando pelos registros em que a sequência candidata está contida na chave e, caso esteja, procura-se tal chave em $I n d_{2}$. Logo, a frequência que a sequência ocorre e o total de séries que a contêm são totalizados para calcular o suporte. Nestas duas etapas, sequências frequentes também são armazenadas em $I n d_{1}$ pois serão úteis na terceira tarefa.

Na terceira tarefa de Mineração de Sequências, para cada sequência frequente com $p$ observações, procura-se outras sequências frequentes com $p$ observações, de modo que as 
$p-1$ últimas observações de uma delas coincida com as $p-1$ primeiras observações da outra. Assim, efetua-se a junção de tais sequências para formar uma sequência candidata com $p+1$ observações, a qual será armazenada caso atenda o threshold de suporte mínimo (sequência frequente). Esta etapa finaliza quando o tamanho da window é alcançado.

Na última tarefa o suporte é calculado da seguinte maneira. Procura-se em Ind 1 cada uma das observações que compõem a sequência candidata, obtendo um Tree Set para cada observação. Se $(i: j)$ pertence ao Tree Set da primeira observação, verifica-se se $(i+p-1: j)$ pertence ao Tree Set da $p$-ésima observação, para $p$ variando de 2 até a quantidade de observações da sequência candidata, sendo que $p$ inicia em 2, pois o caso $p=1$ é trivial já que o processo é iniciado com o Tree Set da primeira observação, então só é necessário verificar as outras observações. Se a resposta for positiva para todos os valores de $p$, existe uma nova ocorrência da sequência candidata que começa no instante $i$ da série $j$.

A complexidade do TRiER é definida pelas etapas de Mineração de Sequências e de Regras de Exceção. A complexidade da primeira etapa é $O\left(\left(w L m D^{w}\right)^{2} \log (L m)\right)$, onde $w$ é o tamanho da window, $L$ é o número de séries temporais do banco de dados, $m$ é o número de observações da série e $D$ é o número de variáveis de cada observação. A complexidade da etapa de Mineração de Regras de Exceção é $O(y w)^{2}$, onde y é o número de sequências geradas.

\subsection{Considerações Finais}

Este capítulo apresentou TRiER, o método precursor em mineração de regras de exceção temporais. TRiER lida com séries temporais multivariadas e aplica uma janela temporal como restrição no processo de descoberta de conhecimento.

TRiER também propõe e implementa uma medida de suporte mais seletiva do que a métrica tradicional. A medida proposta analisa como o potencial padrão ocorre em diferentes observações de uma série e no restante do conjunto de dados. Essa verificação ajuda diferenciar sequências pontuais de padrões efetivamente.

TRiER enriquece o estado da arte em Mineração de Regras de Exceção, uma vez que descobre regras com maior qualidade semântica em relação ao contexto temporal. Além disso, TRiER identifica padrões potencialmente causados por mais de um agente e minera regras que ocorrem em um time lag.

Embora a etapa de Mineração de Sequências tenha uma alta complexidade, sequências com altos e baixos limiares de suporte são geradas em tempos factíveis. Métodos correlatos como GSP, SPADE e Prefix-Span são adequados para descobrir sequências com altos limiares de suporte, mas quando submetidos à mineração de sequências com baixos limiares de suporte, apresentam um grande gargalo de eficiência e eficácia. Gargalo de eficiência porque demandam um tempo infactível para minerar sequências e gargalo de eficácia porque mineram um grande 
volume de padrões, que inclui informações irrelevantes e desnecessárias. Assim, ao invés de criar conhecimento para facilitar a análise de especialistas, este volume de informação poderá exigir uma tarefa de mineração de dados de segunda ordem para eliminar padrões irrelevantes e filtrar os necessários.

Como TRiER implementa uma medida de suporte seletiva, menos sequências são geradas e utilizadas na etapa de Mineração de Regras de Exceção, sendo este o principal diferencial em termos de eficiência e eficácia do método proposto. A Tabela 6 sumariza as principais características dos trabalhos relacionados e do TRiER. As informações revelam que, dentre os trabalhos relacionados, TRiER é o único método que manipula séries temporais e descobre regras potencialmente causadas por mais de um agente.

Tabela 6 - Comparativo do TRiER e Trabalhos Relacionados

\begin{tabular}{|c|c|c|c|c|c|c|}
\hline Algoritmo & Dado & Tempo & Regra Forte & Exceção & Agente & Validação \\
\hline Apriori & Itemset & Não & Sim & Não & Não & Confiança \\
\hline$G S P$ & Sequência & Sim & Não & Não & Não & Não possui \\
\hline SPADE & Sequência & Sim & Não & Não & Não & Não possui \\
\hline Prefix-Span & Sequência & Sim & Não & Não & Não & Não possui \\
\hline$E R S A$ & Itemset & Não & Sim & Sim & Univariado & Fator de certeza \\
\hline TRiER & Série Temporal & Sim & Sim & Sim & Multivariado & Fator de certeza \\
\hline
\end{tabular}



Este capítulo detalha o processo de validação do método proposto por meio da realização de um estudo experimental em dados reais. TRiER foi aplicado em conjuntos de séries agrometeorológicas e do fenômeno El-Niño, a fim de descobrir potenciais comportamentos excepcionais e respectivos agentes causadores. Os principais objetivos do estudo experimental são:

- Definir valores adequados e analisar o impacto dos parâmetros nas tarefas de Mineração de Sequências e Mineração de Regras de Exceção.

- Realizar uma análise comparativa de eficiência das etapas de Mineração de Sequências e Mineração de Regras de Exceção do TRiER frente a métodos propostos na literatura. Para a etapa de Mineração de Sequências, TRiER é comparado com o Prefix-Span. Em Mineração de Regras de Exceção, é comparado ao ERSA, o atual estado da arte, apresentado na Subseção 3.3.1.

- Avaliar a relevância semântica das regras geradas pelo TRiER frente ao método ERSA.

- Estudar a aplicabilidade do TRiER na tarefa de Mineração de Regras de Exceção, com objetivo de oferecer suporte a pesquisas em agrometeorologia e clima.

\subsection{Conjuntos de Dados Reais}

O estudo experimental em dados reais pretende investigar se o método proposto neste trabalho e métodos correlatos podem oferecer suporte eficaz e eficiente para descoberta de conhecimento em agrometeorologia e clima. Este estudo pode ajudar especialistas de domínio a obter novas hipóteses de comportamentos comuns e excepcionais.

Os conjuntos de dados utilizados são: agrometeorológico, apresentado na Subseção 5.1.1, e do fenômeno El-Niño, descrito na Subseção 5.1.2. Analisar dados agrometeorológicos permite 
investigar como eventos climáticos extremos afetam as culturas de cana-de-açúcar no decorrer do tempo. Já nos dados de El-Niño é possível analisar como as variáveis climáticas podem interferir na criticidade do fenômeno.

\subsubsection{Dados Agrometeorológicos}

A agrometeorologia foi considerada como domínio de aplicação por desempenhar um papel fundamental na economia de vários países. No Brasil, por exemplo, contribui com $25 \%$ do PIB e cerca de $40 \%$ da mão-de-obra. Dentre as culturas agrícolas cultivadas no Brasil, este trabalho concentra-se em analisar plantações de cana-de-açúcar.

Neste contexto, a Mineração de Regras de Exceção permite identificar como eventos climáticos extremos afetam plantações de cana-de-açúcar e quanto tempo as implicações demoram para aparecer. Como resultado, ações de controle prévias podem ser implementadas em regiões com características semelhantes às da região estudada, a fim de minimizar os efeitos mais críticos causados por condições climáticas extremas, como secas e chuvas excessivas.

O conjunto de dados agrometeorológico foi construído como segue. Inicialmente, foram coletadas séries temporais de índices vegetativos por meio da ferramenta SATVeg ${ }^{1}$. Esta ferramenta é mantida pela Embrapa ${ }^{2}$ (Empresa Brasileira de Pesquisa Agropecuária) e extrai séries temporais de NDVI (Normalized Difference Vegetation Index) (ROUSE et al., 1974), a partir de séries de imagens do satélite TERRA/MODIS.

O NDVI é um índice utilizado em pesquisas agrícolas e relaciona-se ao vigor vegetativo de determinada região. Este índice varia de -1 a 1 e indica que valores próximos de 1 estão relacionados a forte atividade vegetativa no local. Em contrapartida, valores negativos ou próximos de 0 descrevem áreas com pouca ou nenhuma atividade clorofiliana.

As séries de NDVI coletadas compreendem o período de 2014 a 2018 e são compostas por 60 observações mensais de regiões do estado de São Paulo, o maior estado produtor de cana-de-açúcar do Brasil. Além das séries de NDVI, foram coletadas séries temporais climáticas do INMET $^{3}$ (Instituto Nacional de Meteorologia). Tais séries são multivariadas, compostas por observações mensais de precipitação, temperaturas máxima e mínima.

Para compor o conjunto de dados agrometeorológico, os dados climáticos foram associados aos dados de NDVI considerando a restrição de que um registro de cana deve estar no máximo $70 \mathrm{~km}$ distante (considerando a distância geodésica) de uma estação meteorológica. A Figura 18 ilustra o mapeamento resultante do conjunto de dados agrometeorológico. As regiões de cana-de-açúcar que serão analisadas são representadas por pontos verdes e as estações meteorológicas correspondentes são simbolizadas por estrelas roxas.

1 https://www.satveg.cnptia.embrapa.br/satveg/

2 https://www.embrapa.br/

3 http://www.inmet.gov.br/portal/ 
Figura 18 - Mapeamento do conjunto agrometeorológico: estações meteorológicas e áreas de cana-deaçúcar do estado de São Paulo

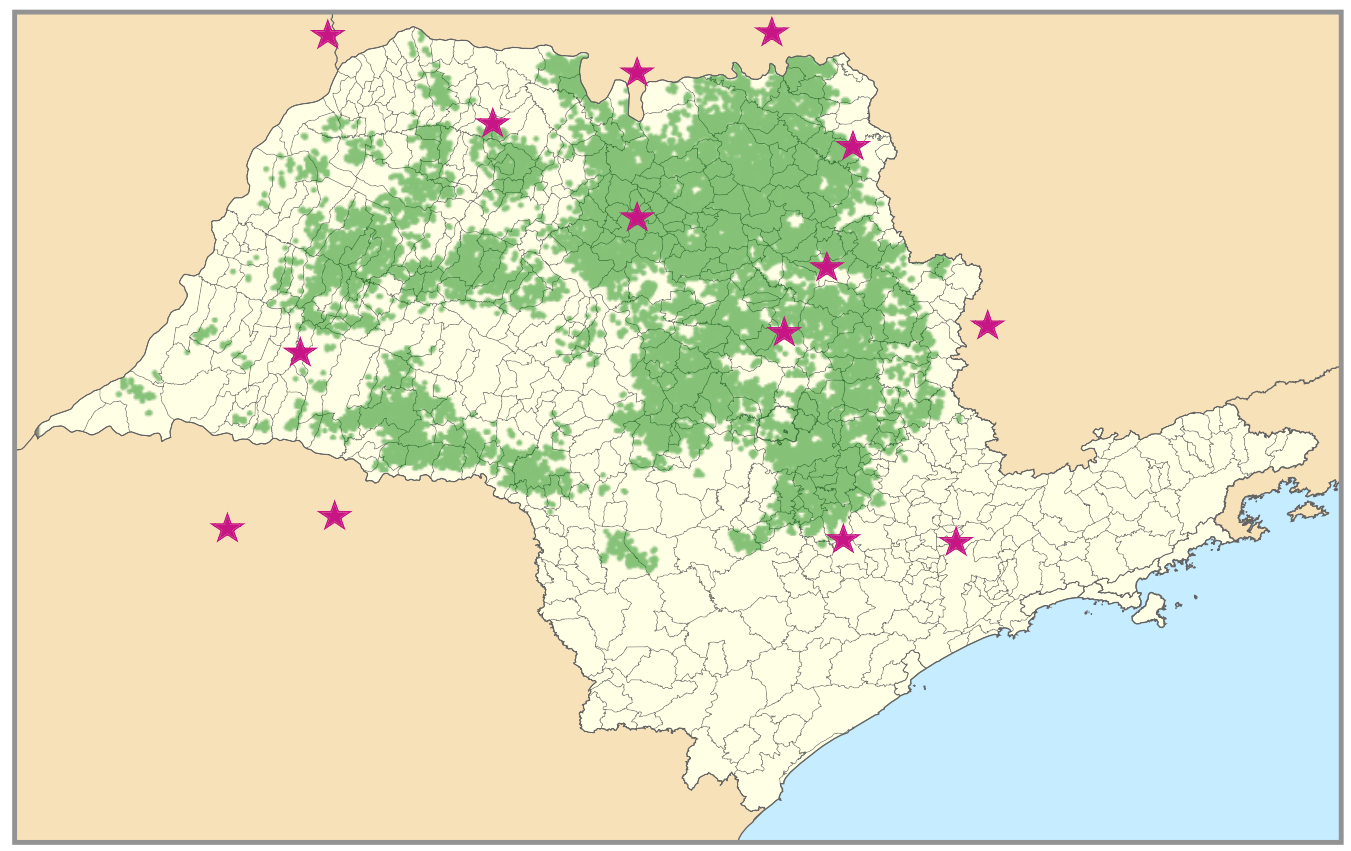

Fonte: Elaborada pelo autor.

A Tabela 7 descreve o conjunto de dados agrometeorológico resultante. MaxTemp, MinTemp, NDVI e Prec são, respectivamente, abreviações de temperatura máxima e mínima, índice $N D V I$ e precipitação.

Tabela 7 - Descrição do Conjunto de Dados Agrometeorológico

\begin{tabular}{c|c|c}
\hline Tamanho da série $(m)$ & Variáveis $(n)$ & Tamanho do conjunto de dados $(L)$ \\
\hline 60 observações & $4=$ MaxTemp, MinTemp, NDVI e Prec & 24.420 séries temporais \\
\hline
\end{tabular}

\subsubsection{Dados de El Niño}

El Niño é um evento climático caracterizado pelo aquecimento anormal das águas do oceano Pacífico, sendo responsável pela alteração do sistema de distribuição de chuvas e calor em diversas regiões do planeta (INPE, 2019). No litoral da América do Sul, por exemplo, ocorre um aumento no volume de chuvas e enchentes. Nas regiões Norte e Nordeste o efeito é reverso e ocorre um aumento significativo no número de incêndios florestais.

Os dados de $\mathrm{El} \mathrm{Niño}{ }^{4}$, disponíveis no repositório Kaggle, são compostos por leituras oceanográficas e meteorológicas diárias obtidas por bóias posicionadas em todo o Pacífico equatorial no período de 1980 a 1998. As variáveis deste conjunto de dados são: intensidade dos ventos meridionais, umidade relativa do ar, temperatura do ar e temperatura da superfície do mar.

4 https://archive.ics.uci.edu/ml/datasets/El+Nino 
Se a granularidade diária das séries fosse mantida, seria necessário aplicar uma janela considerável na etapa de Mineração de Sequências, podendo inviabilizar a aplicação do TRiER e métodos correlatos. Além disso, as relações de causa e consequência em dados climáticos não são instantâneas e, por esse motivo, a granularidade das séries climáticas foi remodelada para mensal. Por fim, restringiu-se como período de investigação os anos de 1997 a 1998, em que o fenômeno foi de forte intensidade.

A Tabela 8 descreve o conjunto de dados resultante. VentMer, Umid, TempMar, TemSup são, respectivamente, abreviações de ventos meridionais, umidade do ar, temperatura da superfície, temperatura da superfície do mar.

Tabela 8 - Descrição do Conjunto de Dados El Niño

\begin{tabular}{c|c|c}
\hline Tamanho da série $(m)$ & Variáveis $(n)$ & Tamanho do conjunto de dados $(L)$ \\
\hline 12 observações & 4 =VentMer, Umid, TempMar, TempSup & 71.885 séries temporais \\
\hline
\end{tabular}

\subsubsection{Representação dos Dados}

Antes de iniciar as etapas do TRiER, as séries temporais precisam ser representadas de uma maneira discreta. Neste contexto, escolheu-se a abordagem equal-width para representação de séries temporais, uma vez que ela satisfaz as premissas definidas na Seção 2.2. As faixas resultantes da discretização equal-width para os conjuntos de dados agrometeorológico e de El-Niño são apresentadas, respectivamente, nas Tabelas 9 e 10:

Tabela 9 - Discretização Equal-Width para os Dados Agrometeorológicos

\begin{tabular}{|c|c|c|c|}
\hline$N D V I$ & TempMax & TempMin & Prec \\
\hline 0.2 a 0.4 & $18^{\circ} \mathrm{C}$ a $20^{\circ} \mathrm{C}$ & $4^{\circ} \mathrm{C} \mathrm{a} 6^{\circ} \mathrm{C}$ & $0 \mathrm{~mm}$ a $50 \mathrm{~mm}$ \\
\hline 0.4 a 0.6 & $20^{\circ} \mathrm{C}$ a $22^{\circ} \mathrm{C}$ & $6^{\circ} \mathrm{C}$ a $8^{\circ} \mathrm{C}$ & $50 \mathrm{~mm}$ a $100 \mathrm{~mm}$ \\
\hline 0.6 a 0.8 & ... & ... & ... \\
\hline 0.8 a 1.0 & $34^{\circ} \mathrm{C}$ a $36^{\circ} \mathrm{C}$ & $20^{\circ} \mathrm{C}$ a $24^{\circ} \mathrm{C}$ & $450 \mathrm{~mm}$ a $500 \mathrm{~mm}$ \\
\hline
\end{tabular}

Tabela 10 - Discretização Equal-Width para os Dados de El-Niño

\begin{tabular}{|c|c|c|c|}
\hline VentMer & TempSup & TempMar & Umid \\
\hline $0 \mathrm{~m} / \mathrm{s}$ a $2 \mathrm{~m} / \mathrm{s}$ & $11.5^{\circ} \mathrm{C}$ a $13.5^{\circ} \mathrm{C}$ & $18.5^{\circ} \mathrm{C}$ a $20.5^{\circ} \mathrm{C}$ & $0 \%$ a $15 \%$ \\
\hline $2 \mathrm{~m} / \mathrm{s}$ a $4 \mathrm{~m} / \mathrm{s}$ & $13.5^{\circ} \mathrm{C}$ a $15.5^{\circ} \mathrm{C}$ & $20.5^{\circ} \mathrm{C}$ a $22.5^{\circ} \mathrm{C}$ & $15 \%$ a $30 \%$ \\
\hline$\ldots$ & $\ldots$ & $\ldots$ & $\ldots$ \\
\hline $16 \mathrm{~m} / \mathrm{s}$ a $18 \mathrm{~m} / \mathrm{s}$ & $31.5^{\circ} \mathrm{C}$ a $33.5^{\circ} \mathrm{C}$ & $28.5^{\circ} \mathrm{C}$ a $30.5^{\circ} \mathrm{C}$ & $75 \%$ a $100 \%$ \\
\hline
\end{tabular}

\subsection{Análise Experimental}

Os experimentos foram realizados em um computador Intel Core i7, $3.40 \mathrm{GHz}$ com 16 GB de RAM e um disco rígido SATA. Os principais resultados obtidos com a realização da análise experimental são sumarizados em dois experimentos: 
1. Mineração de Sequências: investiga e compara a eficiência do método proposto com o Prefix-Span na etapa de Mineração de Sequências. A eficiência é dada pela quantidade de sequências mineradas e o tempo decorrido nesta etapa.

2. Mineração de Regras de Exceção: analisa a eficiência e eficácia do TRiER frente ao estado da arte de mineração de regras de exceção, ERSA. A eficiência é dada pelo tempo gasto na etapa de Mineração de Regras de Exceção e a eficácia é avaliada pela relevância semântica das regras obtidas.

\subsubsection{Mineração de Sequências}

Este experimento tem por objetivo investigar a eficiência do Prefix-Span e TRiER na etapa mais custosa do processo de Mineração de Regras. Assim, analisa-se o tempo gasto por tais métodos à medida que aumenta-se o tamanho da janela $(w)$ e o threshold de suporte mínimo (minsup para os métodos clássicos e minsup $p_{T R E R}$ para o método proposto). Como a granularidade das séries temporais de ambos conjuntos de dados é mensal, o tamanho da janela é dado em meses. Para $w=1$ observação, por exemplo, a janela é de um mês.

A implementação do Prefix-Span utilizada está disponível na ferramenta $\mathrm{SPMF}^{5}$, em que os métodos foram implementados na linguagem Java. Esta ferramenta é referência na área de mineração de padrões, sendo especializada na Mineração de Sequências e itemsets (GAN et al., 2019). A Tabela 11 apresenta o tempo médio de cada algoritmo (em minutos) para os dados agrometeorológicos, em que os dados em verde representam o método que teve performance superior e os dados em vermelho indicam o contrário.

O tamanho máximo de janela avaliado é 5 pois com este threshold o tempo gasto pelos métodos correlatos cresce abruptamente, mostrando que este valor é um gargalo de eficiência para eles. Assim, a avaliação de janela maiores tornaria inviável a excecução deste experimento.

Tabela 11 - Dados Agrometeorológicos: Tempo Médio Gasto em Mineração de Sequências, em Minutos

\begin{tabular}{c|c|c|c|c|c|c|c|c}
\hline \multirow{2}{*}{ Suporte Mínimo } & \multicolumn{2}{|c}{$w=2$} & \multicolumn{2}{c|}{$w=3$} & \multicolumn{2}{c}{$w=5$} \\
\cline { 2 - 9 } & Prefix-Span & TRiER & Prefix-Span & TRiER & Prefix-Span & TRiER & Prefix-Span & TRiER \\
\hline 0.05 & $\mathbf{0 . 0 6 7}$ & 7.416 & $\mathbf{1 . 4 9 4}$ & 19.166 & 34.324 & $\mathbf{2 6 . 5}$ & 811.613 & $\mathbf{2 9 . 7 5}$ \\
\hline 0.1 & $\mathbf{0 . 0 6 6}$ & 3.5 & $\mathbf{1 . 4 2 8}$ & 6.916 & 34.319 & $\mathbf{8 . 5 8 3}$ & 806.415 & $\mathbf{1 0 . 2}$ \\
\hline 0.15 & $\mathbf{0 . 0 6 6}$ & 2.25 & $\mathbf{1 . 4 2 7}$ & 3.833 & 33.906 & $\mathbf{4 . 3 3 3}$ & 784.452 & $\mathbf{6 . 3}$ \\
\hline 0.2 & $\mathbf{0 . 0 6 5}$ & 1.116 & $\mathbf{1 . 4 2 1}$ & 1.916 & 33.346 & $\mathbf{1 . 9 3 5}$ & 735.166 & $\mathbf{3 . 3 8 3}$ \\
\hline 0.3 & $\mathbf{0 . 0 6 5}$ & 0.75 & 1.352 & $\mathbf{0 . 8}$ & 32.744 & $\mathbf{0 . 8 1 6}$ & 648.352 & $\mathbf{1 . 2 5}$ \\
\hline 0.4 & $\mathbf{0 . 0 6 4}$ & 0.383 & 1.319 & $\mathbf{0 . 4 1 6}$ & 32.380 & $\mathbf{0 . 4 6 6 6}$ & 565.446 & $\mathbf{0 . 6 5}$ \\
\hline
\end{tabular}

Pode-se notar que conforme o tamanho da janela aumenta, a performance do PrefixSpan degrada. Isso porque ele implementa uma medida de suporte pouco discriminatória e gera um grande volume de informações irrelevantes e desnecessárias. O aumento do tamanho da janela está diretamente relacionado ao tamanho da sequência. Como a etapa de Mineração

5 http://www.philippe-fournier-viger.com/spmf/ 
de Sequências possui natureza combinatorial sequências maiores demandam maior tempo de execução. A Figura 19 ilustra os dados da Tabela 11.

Figura 19 - Dados agrometeorológicos: tempo médio gasto em mineração de sequências, em minutos
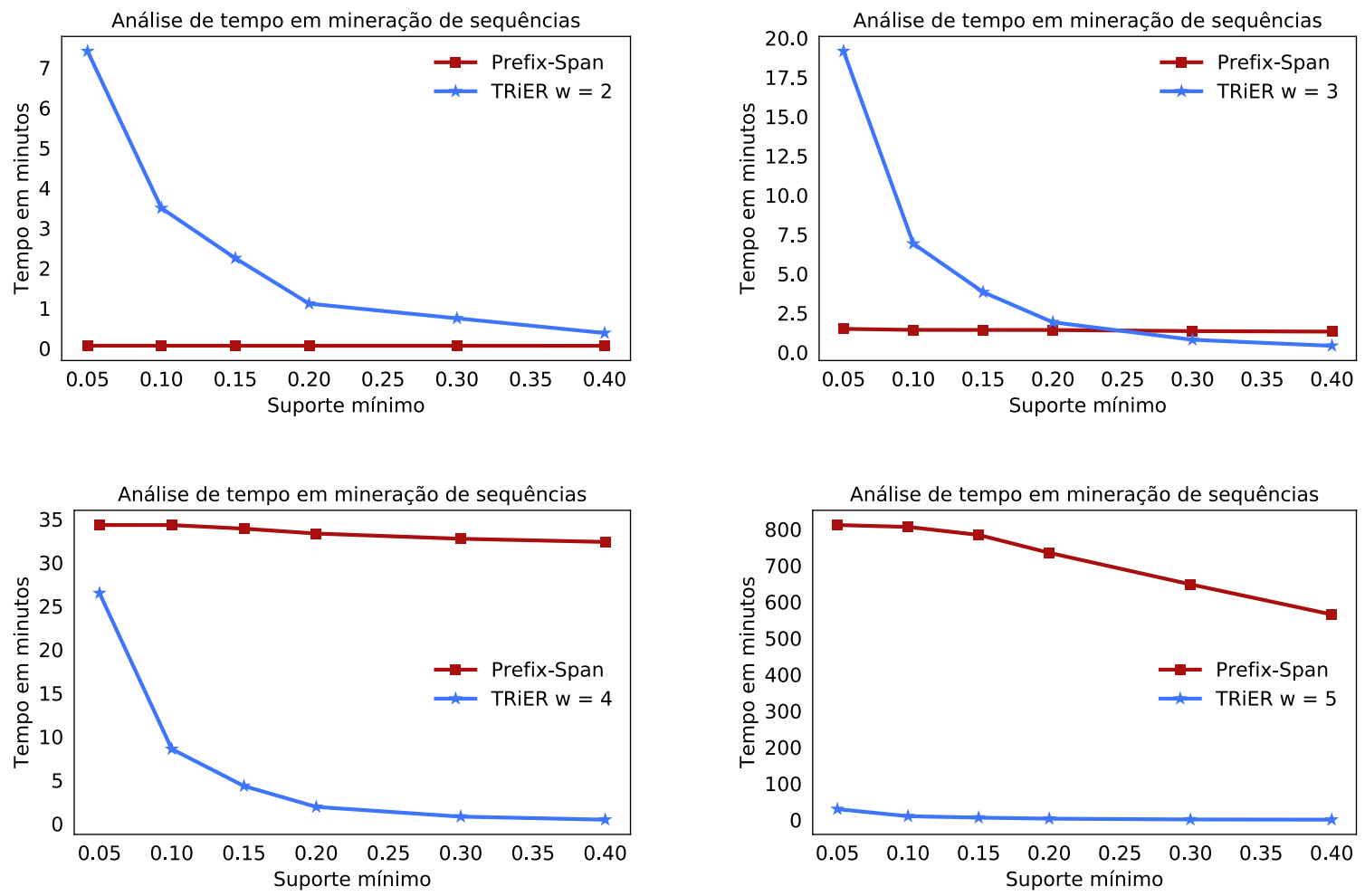

Fonte: Elaborada pelo autor.

Para janelas pequenas, TRiER minera sequências em tempo de execução viável, embora não alcance o desempenho do Prefix-Span, que utiliza uma abordagem de projeção do banco de dados. Entretanto, quando o threshold de suporte mínimo aumenta, a taxa de crescimento do tempo gasto para Mineração de Sequências do TRiER é mais estável e consideravelmente menor do que a do Prefix-Span.

O gargalo de eficiência do Prefix-Span está na Mineração de Sequências maiores (janelas de tamanho 4 e 5, por exemplo) combinadas com baixos limiares de suporte. A Mineração de Sequências maiores é relevante em domínios de aplicação em que deseja-se realizar análises a longo prazo. Já a Mineração de Sequências com baixos valores de suporte é interessante em domínios em que pretende-se descobrir padrões atípicos. TRiER, por outro lado, tem performance superior nesses casos, porque implementa uma medida de suporte seletiva que limita de modo expressivo o número de sequências geradas e, consequentemente, minimiza o tempo necessário para gerar combinações de sequências maiores. A Tabela 12 compara o ganho médio dos dois métodos para os diferentes thresholds de suporte.

A Figura 20 ilustra o crescimento significativo no número de sequências mineradas pelo Prefix-Span em função do tamanho da janela. Para janelas pequenas (2 e 3), o número de 
Tabela 12 - Comparação do Ganho Médio entre os Métodos TRiER e Prefix-Span

\begin{tabular}{c|c|c}
\hline Método & Window & Ganho \\
\hline \multirow{2}{*}{ Prefix-Span } & 2 & $38 x$ mais rápido em média do que o TRiER \\
\cline { 2 - 3 } & 3 & $3 x$ mais rápido em média do que o TRiER \\
\hline \multirow{2}{*}{ TRiER } & 4 & $23 x$ mais rápido em média do que oPrefix-Span \\
\cline { 2 - 3 } & 5 & $300 x$ mais rápido em média do que o Prefix-Span \\
\hline
\end{tabular}

sequências é factível, 1.397 e 50.515 respectivamente. Para janelas maiores (4 e 5), o número de sequências cresce drasticamente, 1.693.404 e 52.520.544 respectivamente. Neste cenário, este volume de regras demandará uma tarefa de mineração de dados de segunda ordem para eliminar padrões irrelevantes e filtrar os realmente necessários.

Figura 20 - Dados agrometeorológicos: sequências geradas pelo TRiER e Prefix-Span para 5\% de suporte

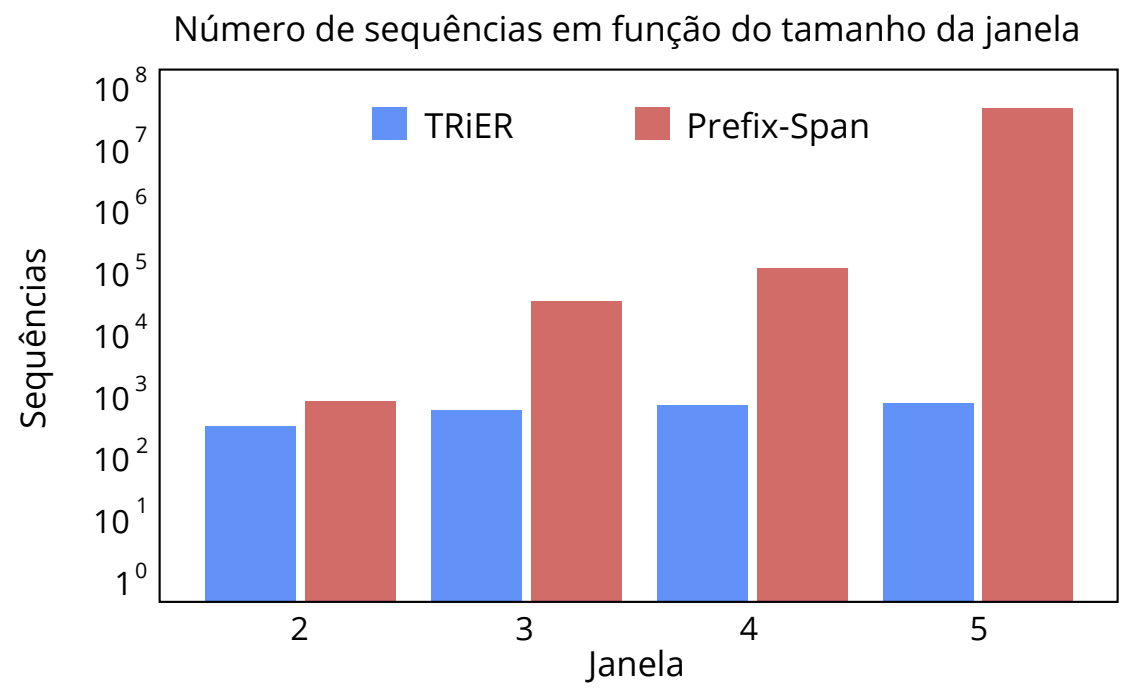

Fonte: Elaborada pelo autor.

A Tabela 13 apresenta os resultados do experimento para os dados de El-Niño e a Figura 21 ilustra os dados desta Tabela. De modo análogo aos dados agrometeorológicos, os resultados obtidos evidenciam que grandes tamanhos de janela e baixos thresholds de suporte mínimo são gargalos de eficiência para o método Prefix-Span.

Tabela 13 - Dados de El-Niño: Tempo Médio Gasto em Mineração de Sequências, em Minutos

\begin{tabular}{c|c|c|c|c|c|c|c|c}
\hline \multirow{2}{*}{ Suporte Mínimo } & \multicolumn{2}{|c|}{$w=2$} & \multicolumn{2}{c|}{$w=3$} & \multicolumn{2}{c}{$w=4$} & \multicolumn{2}{c}{$w=5$} \\
\cline { 2 - 9 } & Prefix-Span & TRiER & Prefix-Span & TRiER & Prefix-Span & TRiER & Prefix-Span & TRiER \\
\hline 0.05 & $\mathbf{0 . 0 3 5}$ & 3.216 & $\mathbf{1 . 7 8 5}$ & 13.263 & 37.254 & $\mathbf{2 1 . 5 1 2}$ & 918.356 & 23.705 \\
\hline 0.1 & $\mathbf{0 . 0 3 4}$ & 2.2 & $\mathbf{1 . 6 8 3}$ & 4.610 & 36.960 & $\mathbf{5 . 3 1 5}$ & 910.563 & 8.42 \\
\hline 0.15 & $\mathbf{0 . 0 3 2}$ & 1.75 & $\mathbf{1 . 5 7 2}$ & 3.133 & 32.920 & $\mathbf{3 . 5 3 3}$ & 874.512 & 5.53 \\
\hline 0.2 & $\mathbf{0 . 0 3 1}$ & 1.216 & $\mathbf{1 . 4 3 6}$ & 1.610 & 31.546 & $\mathbf{1 . 8 5 5}$ & 832.266 & 2.658 \\
\hline 0.3 & $\mathbf{0 . 0 3 0}$ & 0.65 & 1.320 & $\mathbf{0 . 5 1}$ & 30.440 & $\mathbf{0 . 6 7}$ & 756.535 & 1.953 \\
\hline 0.4 & $\mathbf{0 . 0 2 9}$ & 0.23 & 1.120 & $\mathbf{0 . 3 6}$ & 29.850 & $\mathbf{0 . 5 6}$ & 698.446 & 0.85 \\
\hline
\end{tabular}


Figura 21 - Dados de El-Niño: tempo médio gasto em mineração de sequências, em minutos
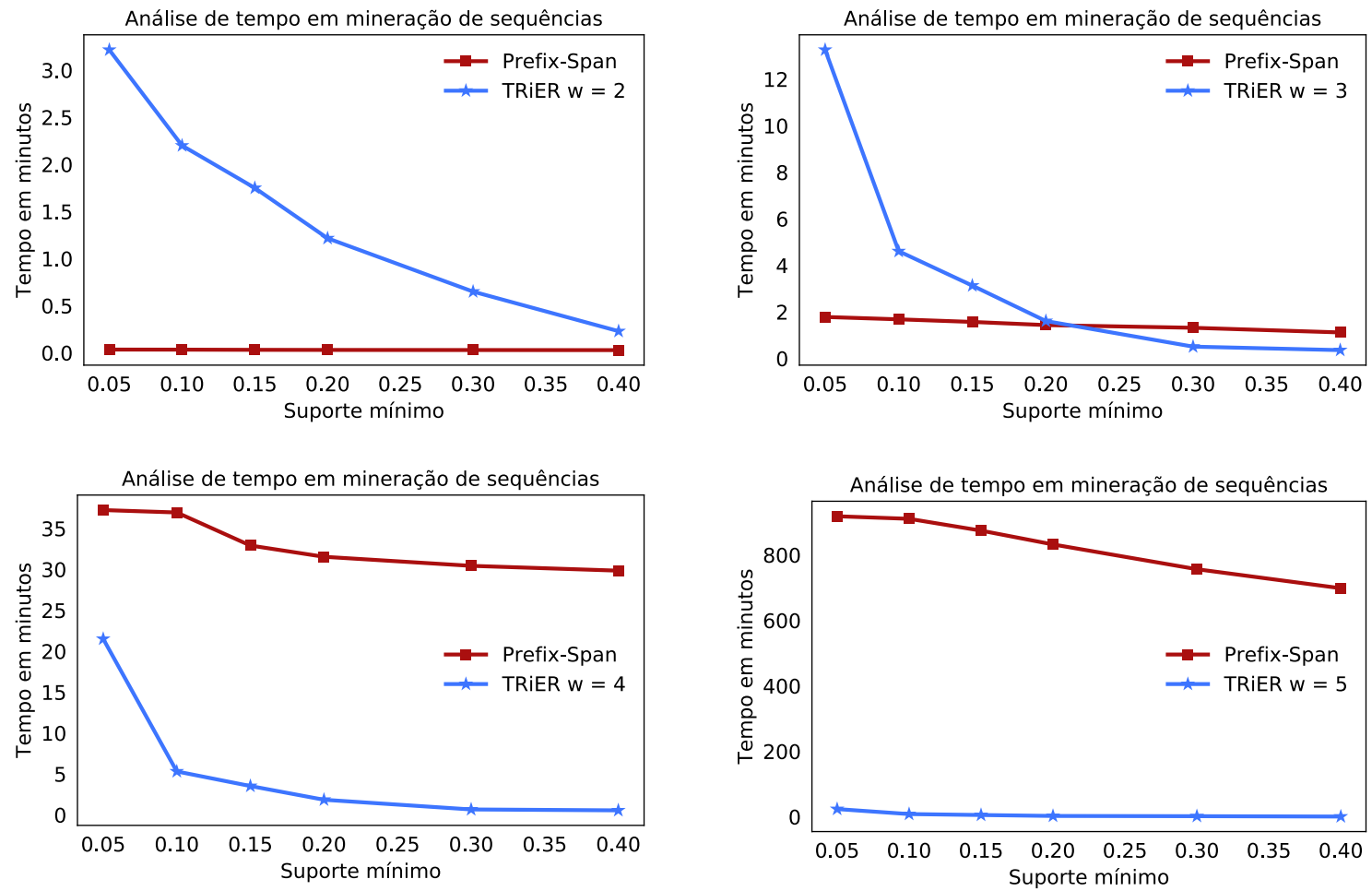

Fonte: Elaborada pelo autor.

A Figura 22 ilustra o número de sequências mineradas pelo Prefix-Span e TRiER em função do tamanho da janela para os dados de El-Niño. Para janelas de tamanho 2 e 3, o número de sequências é 5.457 e 63.635 respectivamente. Para janelas de tamanho 4 e 5 , o número de sequências cresce drasticamente, 3.526 .544 e 65.530 .625 respectivamente.

Figura 22 - Dados de El-Niño: sequências geradas pelo TRiER e Prefix-Span para 5\% de suporte

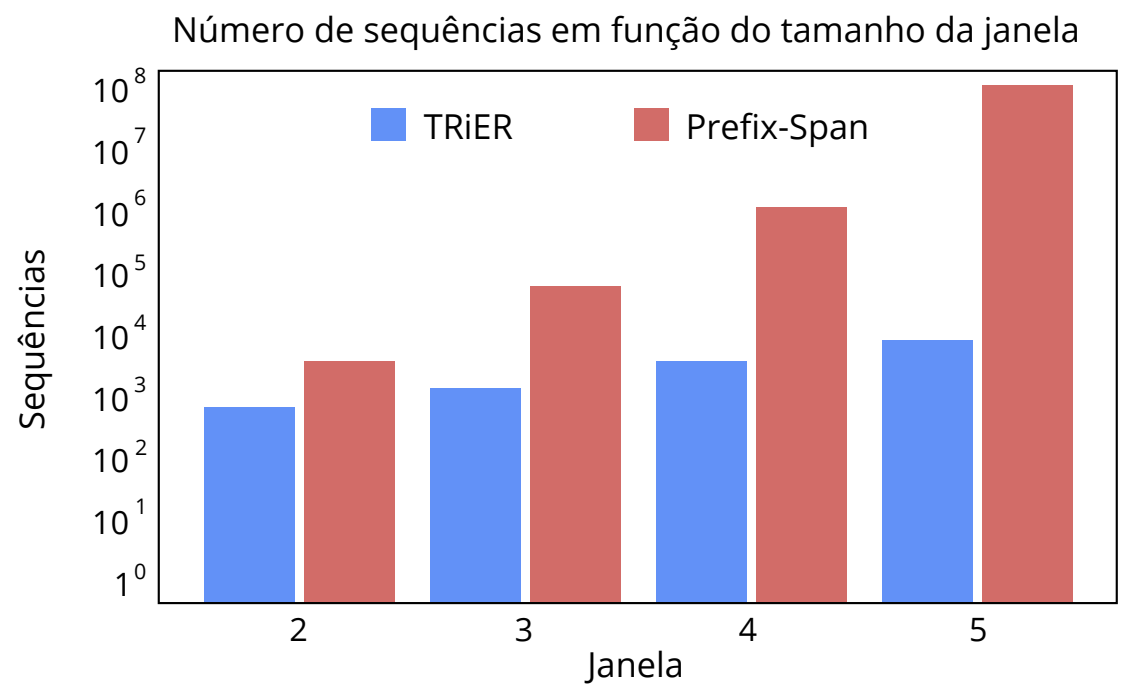

Fonte: Elaborada pelo autor. 


\subsubsection{Mineração de Regras de Exceção}

Este experimento propõe investigar a eficiência, eficácia e utilidade do TRiER frente ao estado da arte para Mineração de Regras de Exceção, ERSA. Os resultados são analisados sob duas perspectivas: o tempo necessário para descobrir regras de exceção e a relevância semântica dos padrões obtidos. TRiER e ERSA foram avaliados com os mesmos thresholds de janela utilizados no experimento de Mineração de Sequências, isto é $w=\{2,3,4,5\}$. O tamanho máximo de janela avaliado também é 5 pois com este threshold o tempo gasto pelo método correlato cresce excessivamente, mostrando que este valor é um gargalo de eficiência.

A Figura 23 e a Figura 24 ilustram o tempo gasto pelo ERSA e TRiER para os dados agrometeorológicos e de El-Niño com diferentes configurações de janela e suporte mínimo. Pode-se notar que independente do tamanho de janela e do threshold de suporte mínimo, TRiER possui a melhor performance.

Figura 23 - Dados agrometeorológicos: tempo médio gasto pelo ERSA e TRiER na mineração de regras de exceção

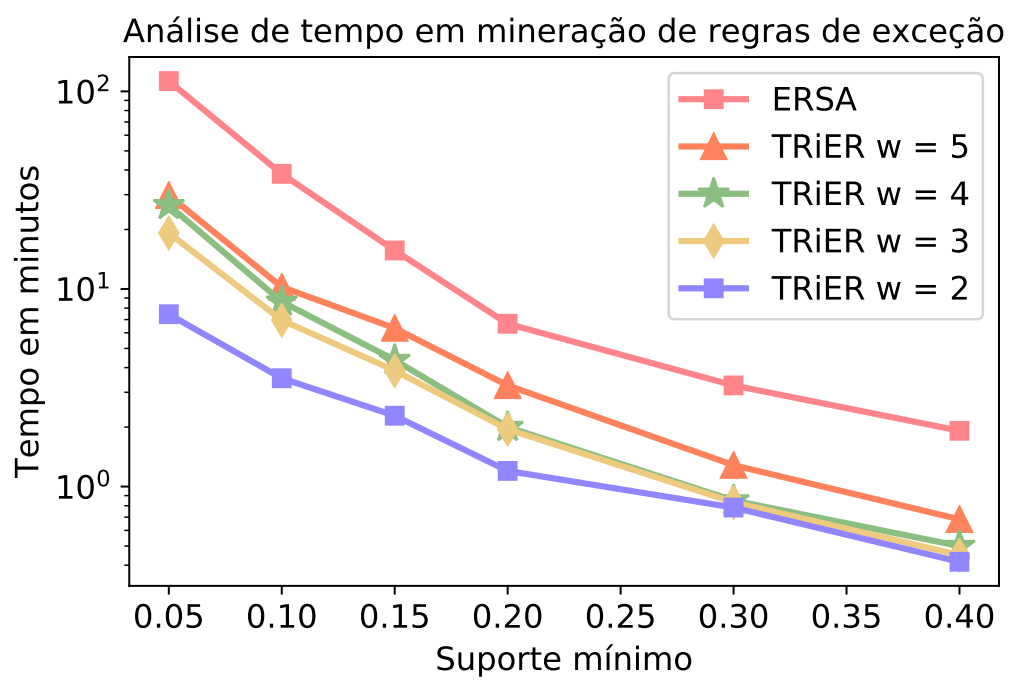

Fonte: Elaborada pelo autor.

Como ERSA gera um grande volume de regras, os tempos apresentados nas Figuras $23 \mathrm{e}$ 24 foram medidos com $60 \%$ de fator de certeza. Regras geradas apenas com confiança ou valores inferiores de fator de certeza excederam os recursos de memória e processamento disponíveis para realizar o experimento. Para maiores thresholds de fator de certeza $(70 \%, 80 \%, 90 \%, 95 \%)$, TRiER ainda possui a melhor performance.

Um dos problemas que degrada a performance do ERSA é a maneira como ele procura por exceções. As regras são armazenadas em um único conjunto, sem distinção de regras fortes e infrequentes. Assim, para cada regra forte, este conjunto é inteiramente verificado para identificar uma potencial regra de exceção. Esta etapa é um de seus gargalos de eficiência e eficácia. Gargalo de eficiência porque o conjunto tende a ser grande e é totalmente verificado toda vez que uma 
Figura 24 - Dados de El-Niño: tempo médio gasto pelo ERSA e TRiER na mineração de regras de exceção

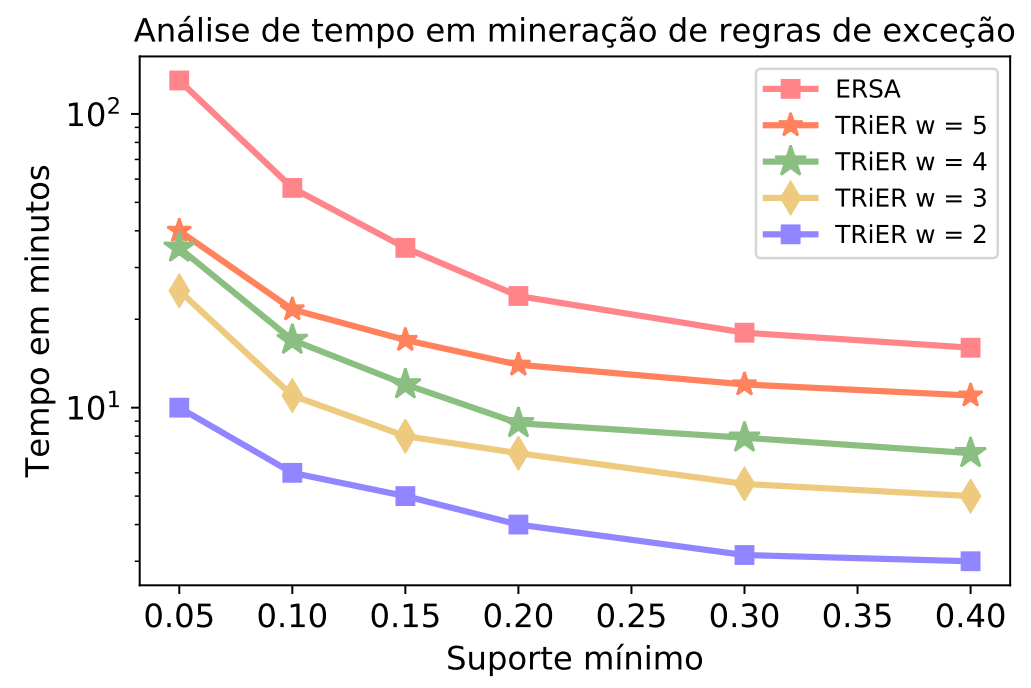

Fonte: Elaborada pelo autor.

regra forte é encontrada. Gargalo de eficácia porque muitas regras desnecessárias e irrelevantes podem ser interpretadas como exceção, o que pode dificultar e confundir a análise do especialista.

Por outro lado, TRiER classifica as regras descobertas entre fortes e infrequentes. Para cada regra forte, o conjunto de regras infrequentes é analisado para descobrir uma exceção que atenda às premissas definidas no Capítulo 4. Especificamente, TRiER não percorre todo o conjunto de regras, mas apenas as classificadas como infrequentes, um conjunto muito menor.

A fim de comparar o ERSA com o TRiER é necessário que ambos os métodos sejam capazes de entender séries temporais. TRiER nativamente suporta séries temporais mas para o ERSA foram necessárias algumas adaptações. A Figura 25 ilustra este procedimento. O ajuste consiste em transformar cada série temporal em uma tupla binária, em que cada observação é um subbloco nesta tupla.

Da maneira como foi projetado, ERSA gera $2^{d}$ candidatos, onde $d$ representa o número de símbolos utilizados na representação. Para os dados agrometeorológicos $d=32$ e para os dados de $E l$-Niño $d=32$. Desse modo, simplificou-se o tamanho máximo de itemset para 5 em ambos conjuntos de dados, caso contrário, a realização deste experimento tornaria-se impraticável em termos de memória e processamento. Neste contexto, o número de possíveis candidatos é dado pela quantidade de conjuntos com até 5 elementos que podem ser formados com o número de símbolos da representação. Com essa simplificação, o número de candidatos reduz para aproximadamente 240.000 nos dados agrometeorológicos:

$$
C_{32,5}+C_{32,4}+C_{32,3}+C_{32,2}+C_{32,1} \approx 240.000 \text { candidatos }
$$


Figura 25 - Transformação de séries temporais em itemset sem perder a informação temporal

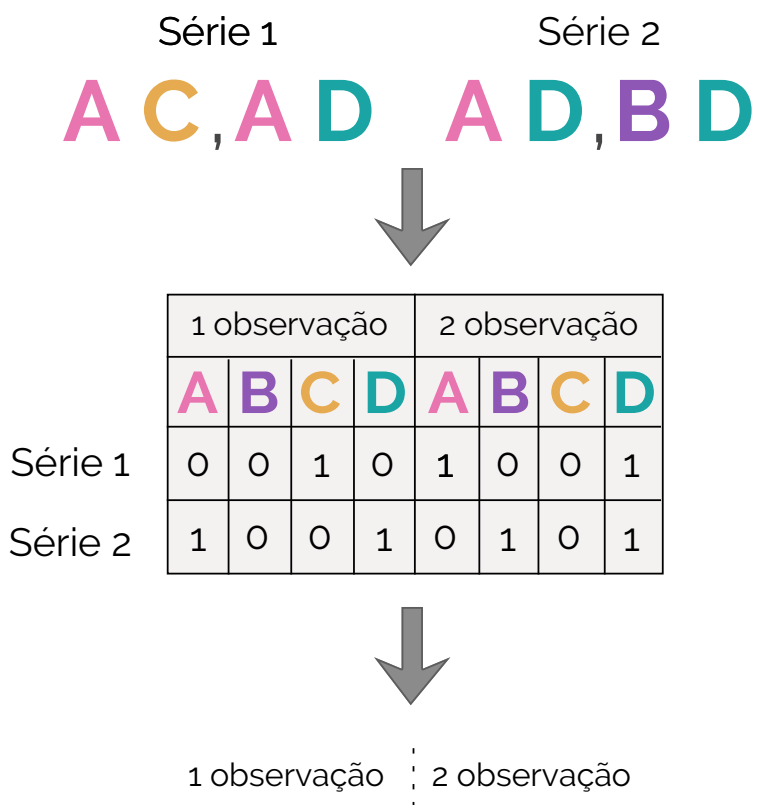

\section{Série $11010: 1001$}

\section{Série $21001: 0101$}

Fonte: Elaborada pelo autor.

Note que $C_{32, i}$ é o total de itemsets com exatamente $i$ elementos, obtido pela Equação 5.1.

$$
C_{n, k}=\frac{n !}{(n-k) ! k !}
$$

Para fundamentar a análise semântica das regras mineradas, a seguir são apresentados alguns exemplos de regras geradas pelo TRiER e ERSA. Retomando a definição de regras de exceção: $X$ é o antecedente da regra, $E$ é o agente causador da exceção, $\neg Y$ é o comportamento excepcional e $Y$ é o comportamento esperado. Para os dados agrometeorológicos, temperaturas são medidas em graus Celsius, precipitação em milímetros e time lag em meses.

1. Regra Forte: Se a temperatura mínima variar entre $18^{\circ} \mathrm{C}$ e $20^{\circ} \mathrm{C}$, o $N D V I$ permanece entre 0.6 e 0.8 no próximo mês. Suporte: $75.27 \%$, confiança: $68.79 \%$ e fator de certeza: $63.45 \%$.

Regra de Exceção: Se a temperatura mínima permanecer com este valor e a precipitação for baixa e variar entre $0 \mathrm{~mm}$ e $20 \mathrm{~mm}$, o NDVI diminui no mês seguinte e varia entre $0.2 \mathrm{e}$ 0.4. Suporte: $5.09 \%$, confiança: $74.38 \%$ e fator de certeza: $69.17 \%$.

2. Regra Forte: Se a temperatura máxima variar entre $28^{\circ} \mathrm{C}$ e $30^{\circ} \mathrm{C}$, o $N D V I$ permanece entre 0.4 e 0.6 no próximo mês. Suporte: $83.71 \%$, confiança: $78.14 \%$ e fator de certeza: 
$69.53 \%$.

Regra de Exceção: Se a temperatura máxima permanecer com este valor e a precipitação for excessiva e variar entre $450 \mathrm{~mm}$ e $500 \mathrm{~mm}$, o $N D V I$ aumenta no mês seguinte e varia entre 0.6 e 0.8 . Suporte: $9.82 \%$, confiança: $84.53 \%$ e fator de certeza: $70.96 \%$.

3. Regra Forte: Se a temperatura mínima variar entre $20^{\circ} \mathrm{C}$ e $22^{\circ} \mathrm{C}$, o $N D V I$ permanece entre 0.6 e 0.8 no próximo mês. Suporte: $85.41 \%$, confiança: $75.23 \%$ e fator de certeza: $71.67 \%$.

Regra de Exceção: Se a temperatura mínima permanecer com este valor, a temperatura máxima variar entre $30^{\circ} \mathrm{C}$ e $32^{\circ} \mathrm{C}$ e a precipitação variar entre $100 \mathrm{~mm}$ e $150 \mathrm{~mm}$, o $N D V I$ atinge seu máximo valor no mês seguinte e varia entre 0.8 e 1.0. Suporte: $14.25 \%$, confiança: $85.47 \%$ e fator de certeza: $79.63 \%$.

Essas regras podem ser validadas por estudos da área, em que especialistas afirmam que períodos de baixa precipitação prejudicam as culturas de cana-de-açúcar e são responsáveis pela redução dos valores de NDVI. Em contrapartida, chuvas intensas estão relacionadas ao aumento dos valores de NDVI (LUCAS; SCHULER, 2007). Por fim, temperaturas elevadas e chuvas regulares são ideais para o vigor vegetativo das plantações de cana-de-açúcar e refletem nos valores máximos de NDVI. Para os dados de El-Niño, VentMer, Umid, TempMar, TemSup e Intens são exemplos de regras mineradas:

1. Regra Forte: Se os ventos meridionais variarem entre $8 \mathrm{~m} / \mathrm{s}$ e $10 \mathrm{~m} / \mathrm{s}$, a temperatura da superfície varia entre $23.5^{\circ} \mathrm{C}$ e $25.5^{\circ} \mathrm{C}$ após três meses. Suporte: $65.57 \%$, confiança: $76.12 \%$ e fator de certeza: $70.44 \%$.

Regra de Exceção: Se os ventos meridionais permanecerem com este valor, mas diminuirem após dois meses e variarem entre $2 \mathrm{~m} / \mathrm{s}$ e $4 \mathrm{~m} / \mathrm{s}$, a temperatura da superfície aumenta e varia entre $27.5^{\circ} \mathrm{C}$ e $29.5^{\circ} \mathrm{C}$ daqui três meses. Suporte: $8.13 \%$, confiança: $81.34 \%$ e fator de certeza: $76.45 \%$.

2. Regra Forte: Se os ventos meridionais variarem entre $10 \mathrm{~m} / \mathrm{s}$ e $12 \mathrm{~m} / \mathrm{s}$, a temperatura da superfície do mar varia entre $22.5^{\circ} \mathrm{C}$ e $24.5^{\circ} \mathrm{C}$ após dois meses. Suporte: $61.34 \%$, confiança: $72.32 \%$ e fator de certeza: $71.67 \%$.

Regra de Exceção: Se os ventos meridionais permanecerem com este valor e a umidade variar entre $15 \%$ e $30 \%$, a temperatura da superfície do mar aumenta e varia entre $26.5^{\circ} \mathrm{C}$ e $28.5^{\circ} \mathrm{C}$ daqui dois meses. Suporte: $8.25 \%$, confiança: $82.30 \%$ e fator de certeza: $76.71 \%$.

Essas regras são corroboradas pelo conhecimento existente sobre o fenômeno El-Niño, que afirma que ventos de fraca intensidade estão associados ao aumento de temperatura da superfície terrestre e que quando combinados com baixa umidade, potencializam o aumento da temperatura da superfície do mar (MARCUZZO; ROMERO, 2013). 
As regras geradas pelo ERSA são semanticamente incompletas porque permitem apenas inferir sobre relacionamentos e não consideram o aspecto temporal. A seguir são apresentados alguns exemplos de regras mineradas pelo ERSA para ambos os conjuntos de dados.

1. Regra Forte: Se a temperatura mínima variar entre $18^{\circ} \mathrm{C}$ e $20^{\circ} \mathrm{C}$ o $N D V I$ varia entre 0.4 e 0.6. Suporte: $58.53 \%$, confiança: $61.20 \%$ e fator de certeza: $60.43 \%$.

Regra de Exceção: Se a temperatura mínima permanecer com este valor e a precipitação variar entre $200 \mathrm{~mm}$ e $250 \mathrm{~mm}$, o $N D V I$ varia entre 0.6 e 0.8 . Suporte: $54.13 \%$, confiança: $65.78 \%$ e fator de certeza: $59.58 \%$.

2. Regra Forte: Se a temperatura máxima variar entre $30^{\circ} \mathrm{C}$ e $32^{\circ} \mathrm{C}$, o $N D V I$ varia entre 0.6 e 0.8 .

Regra de Exceção: Se a temperatura máxima permanecer com este valor e a temperatura mínima variar entre $8^{\circ} \mathrm{C}$ e $10^{\circ} \mathrm{C}$, o $N D V I$ varia entre 0.4 e 0.6 . Suporte: $39.25 \%$, confiança: $78.30 \%$ e fator de certeza: $62.25 \%$.

3. Regra Forte: Se a temperatura da superfície variar entre $23.5^{\circ} \mathrm{C}$ e $25.5^{\circ} \mathrm{C}$, a temperatura da superfície do mar varia entre $22.5^{\circ} \mathrm{C}$ e $24.5^{\circ} \mathrm{C}$. Suporte: $55.12 \%$, confiança: $66.22 \%$ e fator de certeza: $62.17 \%$.

Regra de Exceção: Se a temperatura da superfície permanecer com este valor e a umidade variar entre $30 \%$ e $45 \%$, a temperatura da superfície do mar varia entre $26.5^{\circ} \mathrm{C}$ e $28.5^{\circ} \mathrm{C}$. Suporte: $63.56 \%$, confiança: $61.22 \%$ e fator de certeza: $60.45 \%$.

\subsection{Considerações Finais}

Neste capítulo foi apresentado o estudo experimental para validação das etapas do TRiER. Foram utilizados dados reais correspondentes a séries agrometeorológicas e climáticas relacionadas ao fenômeno El-Niño. TRiER mostrou-se superior ao clássico e eficiente método de Mineração de Sequências, Prefix-Span à medida que o tamanho do problema se escala.

Além disso, o número de sequências mineradas pelo TRiER é significativamente menor do que a quantidade gerada pelo Prefix-Span. A vantagem em gerar menos informações está diretamente associada a qualidade dos padrões obtidos e no esforço do especialista em analisá-los. Um conjunto conciso possui uma quantidade menor de padrões irrelevantes e desnecessários, além de ser mais fácil de manipular e interpretar.

Na etapa de Mineração de Regras de Exceção, TRiER mostrou-se superior para os diferentes tamanhos de janela e thresholds de suporte mínimo, além de gerar regras com maior relevância semântica em relação à temporalidade. Assim, as regras descobertas e validadas com o conhecimento existente sobre assunto, indicam que TRiER é capaz de descobrir padrões semanticamente interessantes e fundamentados. 

No cenário atual, em que grande parte dos dados gerados em diversas áreas de pesquisa e aplicação são temporais, o desenvolvimento de métodos computacionais eficientes e escaláveis para a extração de conhecimento relevante e útil é uma tarefa importante. Dentre as abordagens existentes para esta finalidade, este trabalho fundamentou-se nas tarefas de Descoberta de Regras de Associação, Mineração de Sequências e Mineração de Regras de Exceção.

Enquanto tarefa de Descoberta de Regras de Associação encontra relacionamentos frequentes e confiáveis nas bases de dados e originalmente é restrita à manipulação de bancos transacionais, em que não há organização temporal, a tarefa de Mineração de Sequências descobre sequências frequentes que ocorrem ordenadas como padrões e, em geral, não estabelece relações de causa e consequência, permitindo apenas inferir sobre a ordem que as informações ou eventos ocorreram. Entretanto, em alguns casos há interesse na descoberta de padrões que apesar de serem infrequentes podem ser críticos. Esta classe de padrão denomina-se regras de exceção.

A junção das características de cada uma dessas tarefas constitui o método precursor de Mineração de Regras de Exceção Temporais desenvolvido neste trabalho, denominado TRiER

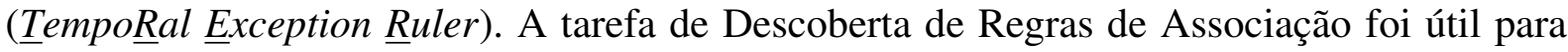
identificar regras fortes, que expressam o comportamento comum, enquanto a tarefa de Mineração de Sequências foi utilizada para descobrir sequências frequentes que formam potenciais regras fortes e de exceção. Por fim, a tarefa de Mineração de Regras de Exceção possibilitou a descoberta de comportamentos incomuns e respectivos agentes causadores.

A principal característica do método proposto é a utilização de uma janela que permite a descoberta de padrões que ocorrem um lag temporal. TRiER é o precursor na área de Mineração de Regras de Exceção com suporte a séries temporais multivariadas. Neste contexto, TRiER não apenas descobre comportamentos comuns (regras fortes) e suas contradições (regras de exceção), mas também identifica quanto tempo as consequências demoram para aparecer e os diferentes agentes que podem ter causado o comportamento excepcional. As contribuições 
apresentadas nesta dissertação mostraram-se úteis para o endereçamento de problemas da área de agrometeorologia e clima, ampliando a possibilidade de realização de estudos que requerem suporte computacional nestes domínios de aplicação.

\subsection{Principais Contribuições}

TRiER difere-se dos métodos correlatos e amplia o estado da arte na tarefa de Mineração de Regras de Exceção nos seguintes aspectos:

- Propõe, implementa e valida um método para Mineração de Regras de Exceção Temporais que manipula séries temporais e possui complexidade computacional inferior ao estado da arte, descobre regras com maior relevância semântica em relação à temporalidade, minera regras potencialmente causadas por agentes multivariados. TRiER também apresentou performance superior ao ERSA, o atual estado da arte em Mineração de Regras de Exceção.

- Desenvolvimento de um método em que a etapa de Mineração de Sequências é mais escalável do que o Prefix-Span, um dos principais e mais eficientes métodos desta tarefa. TRiER possui performance significativamente melhor durante a Mineração de Sequências com janelas maiores e baixos limiares de suporte.

- Propõe e implementa uma nova medida de suporte para manipulação de séries temporais que reduz significativamente o número de padrões obtidos, resultando em um conjunto de regras manipulável e fácil de ser interpretado por especialistas de domínio. A medida proposta também pode ser reutilizada por outros métodos que manipulam séries temporais.

- Análise experimental em dados reais de agrometeorologia e do fenômeno El-Niño, fornecendo potencial conhecimento adicional para estes domínios de aplicação.

- Elaboração do conjunto de dados agrometeorológico, que pode ser utilizado em outras pesquisas e estudos da área.

Os resultados deste trabalho de mestrado resultaram no artigo científico: "TRiER: A Fast and Scalable Method for Mining Temporal Exception Rules", que foi publicado no $34^{\circ}$ Simpósio Brasileiro de Banco de Dados (SBBD 2019), em Fortaleza, Ceará. O artigo foi premiado como best paper e recebeu o prêmio José Mauro de Castilho.

\subsection{Trabalhos Futuros}

O trabalho desenvolvido representa um ponto de partida para a realização de pesquisa em diferentes vertentes de trabalhos futuros. As principais propostas são: 
- Utilização, adaptação ou desenvolvimento de um método de representação de séries temporais para mineração de padrões infrequentes.

- Adaptação ou desenvolvimento de novas métricas para avaliação de padrões excepcionais.

- Implementar os conceitos de banco de dados vertical ou projeção do banco de dados na etapa de Mineração de Sequências. 



\section{REFERÊNCIAS}

AGRAWAL, R.; IMIELINSKI, T.; SWAMI, A. Mining association rules between sets of items in large databases. In: Proceedings of International Conference on Management of Data. New York, NY, USA: ACM Press, 1993. p. 207-216. Citado nas páginas 26, 38, 40 e 41.

AGRAWAL, R.; SRIKANT, R. Mining sequential patterns. In: Proceedings of International Conference on Data Engineering. New York, NY, USA: ACM Press, 1995. p. 3-14. Citado nas páginas 26, 41 e 43.

BERZAL, F.; BLANCO, I.; SáNCHEZ, D.; VILA, M. Measuring the accuracy and interest of association rules: a new framework. Intelligent Data Analysis, p. 221-235, 2002. Citado na página 40.

CANO, M. D.; SANTOS, M. T. P.; AVILA, A. M. H. de; ROMANI, L. A. S.; TRAINA, A. J. M.; RIBEIRO, M. X. Sart: A new association rule method for mining sequential patterns in time series of climate data. In: MURGANTE, B.; GERVASI, O.; MISRA, S.; NEDJAH, N.; ROCHA, A. M. A. C.; TANIAR, D.; APDUHAN, B. O. (Ed.). Computational Science and Its Applications. Berlin, Heidelberg: Springer Berlin Heidelberg, 2012. p. 743-757. Citado na página 40.

CASANOVA, I. J.; CAMPOS, M.; JUAREZ, J.; FERNANDEZ-FERNANDEZ-ARROYO, A.; LORENTE, J. Impact of time series discretization on intensive care burn unit survival classification. Progress in Artificial Intelligence, p. 41-53, 2017. Citado na página 32.

DALY, O.; TANIAR, D. Exception rules in data mining. Applied Mathematics and Computation, p. 735-750, 2008. Citado na página 48.

DELGADO, M.; RUIZ, M. D.; SANCHEZ, D. Studying interest measures for association rules through a logical model. International Journal of Uncertainty, Fuzziness and KnowledgeBased Systems, p. 87-106, 2010. Citado nas páginas 26 e 48.

DONG, G. Sequence data mining. Berlin, Germany: Springer-Verlag, 2009. Citado na página 50 .

FAYYAD, U.; UTHURUSAMY, R. Data mining and knowledge discovery in databases. Commun. ACM, ACM, New York, NY, USA, p. 24-26, 1996. Citado nas páginas 25, 37 e 38.

FOURNIER-VIGER, P.; GOMARIZ, A.; CAMPOS, M.; THOMAS, R. Fast vertical mining of sequential patterns using co-occurrence information. In: Advances in Knowledge Discovery and Data Mining. Cham, Germany: Springer International Publishing, 2014. p. 40-52. Citado na página 43.

GAN, W.; LIN, J. C.; FOURNIER-VIGER, P.; CHAO, H.; YU, P. S. A survey of parallel sequential pattern mining. Transactions on Knowledge Discovery from Data, p. 25:1-25:34, 2019. Citado na página 67. 
HAN, J.; KAMBER, M. Data Mining: Concepts and Techniques. 2nd. ed. Waltham, Massachusetts: Morgan Kaufmann Publishers, 2006. Citado na página 32.

HAN, J.; PEI, J.; YIN, Y. Mining frequent patterns without candidate generation. In: Proceedings of the 2000 ACM SIGMOD International Conference on Management of Data. New York, NY, USA: ACM, 2000. p. 1-12. Citado na página 43.

HUSSAIN, F.; LIU, H.; SUZUKI, E.; LU, H. Exception rule mining with a relative interestingness measure. In: Proceedings of Knowledge Discovery and Data Mining. New York, NY, USA: ACM, 2000. p. 86-97. Citado nas páginas 26, 47 e 48.

INPE, C. MONITORAMENTO DO EL NIÑO DURANTE NDJ-2019/2020. 2019. Disponível em: <http://enos.cptec.inpe.br/saiba/Oque_el-nino.shtml>. Citado na página 65.

KEOGH, E.; CHAKRABARTI, K.; PAZZANI, M.; MEHROTRA, S. Dimensionality reduction for fast similarity search in large time series databases. Knowledge and Information Systems, p. 263-286, 2001. Citado na página 32.

LIN, J.; KEOGH, E.; WEI, L.; LONARDI, S. Experiencing sax: a novel symbolic representation of time series. Data Mining and Knowledge Discovery, p. 107-144, 2007. Citado na página 33.

LUCAS, A.; SCHULER, C. Análise do NDVI/NOAA em cana-de-açúcar na ata Atlântica no litoral norte de Pernambuco, Brasil. Revista Brasileira de Engenharia Agrícola e Ambiental, Scielo, p. 607 - 614, 2007. Citado na página 74.

MAIMON, O.; ROKACH, L. Data Mining and Knowledge Discovery Handbook. 2nd. ed. Berlin, Heidelberg: Springer Publishing Company, 2010. Citado na página 37.

MARCUZZO, F. F. N.; ROMERO, V. Influência do El Niño e La Niña na precipitação máxima diária do estado de Goiás. Revista Brasileira de Meteorologia, Scielo, p. 429 - 440, 2013. Citado na página 74.

MITSA, T. Temporal Data Mining. 1st. ed. [S.1.]: Chapman \& Hall/CRC, 2010. Citado nas páginas $29,30,31$ e 33 .

ORHAN, U.; HEKIM, M.; OZER, M. Epileptic seizure detection using probability distribution based on equal frequency discretization. Journal of Medical Systems, p. 2219-2224, 2012. Citado na página 34.

PEI, J.; HAN, J.; WANG, J.; CHEN, Q. Mining sequential patterns by pattern-growth: the prefix-span approach. Transactions on Knowledge and Data Engineering, p. 1424-1440, 2004. Citado nas páginas 43 e 45.

ROUSE, J. J.; HASS, R. H.; SCHELL, J. A.; DEERING, D. W. Monitoring vegetation systems in the great plains with erts. In: NASA Special Publication. Washington, USA: NASA Astrophysics, 1974. Citado na página 64.

RUIZ, M. D.; SANCHEZ, D.; DELGADO, M.; MARTIN-BAUTISTA, M. J. Discovering fuzzy exception and anomalous rules. Transactions on Fuzzy Systems, p. 930-944, 2016. Citado na página 49. 
SRIKANT, R.; AGRAWAL, R. Mining sequential patterns: Generalizations and performance improvements. In: Advances in Database Technology. Berlin, Heidelberg: Springer Berlin Heidelberg, 1996. p. 1-17. Citado na página 43.

SULAIMAN, N. S.; BAKAR, R. A. Rough set discretization: Equal frequency binning, entropy/mdl and semi naives algorithms of intrusion detection system. In: International Conference on the Applications of Digital Information and Web Technologies. New York, NY, USA: ACM, 2016. Citado na página 34.

SUZUKI, E. Discovering unexpected exceptions: a stochastic approach. Proceedings of Rough Sets, Fuzzy Sets, and Machine Discovery, Tokyo University Press, Workshop Rough Sets, Fuzzy Sets, and Machine Discovery, p. 259-262, 1996. Citado nas páginas 26, 47 e 48.

ZAKI, M. J. Scalable algorithms for association mining. Transactions on Knowledge and Data Engineering, IEEE Educational Activities Department, Piscataway, NJ, USA, p. 372-390, 2000. Citado na página 40.

Spade: An efficient algorithm for mining frequent sequences. Machine Learning, $p$. 31-60, 2001. Citado nas páginas 43 e 44. 


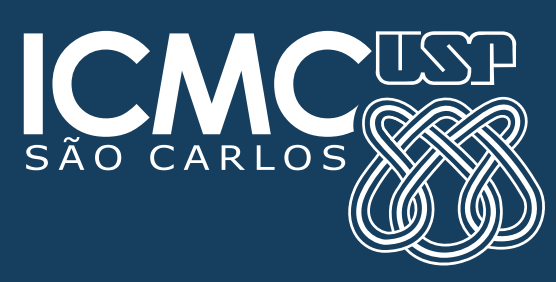

